\title{
البحث الرابـر:
}

واتع مهمارسة طالبات جامعة الإهام مصمد بنِ سعود الإسلاهية لمهارات التعلم المنظم ذاتياً

$$
\begin{aligned}
& \text { إلحاكاك } \\
& \text { د / تهاني بنت خالد بن محمد الجبير }
\end{aligned}
$$

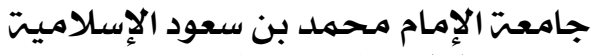

$$
\begin{aligned}
& \text { المملكت العربيت السعوديت }
\end{aligned}
$$



د / تهاني بنت خالد بن محممد الجبير

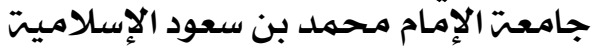

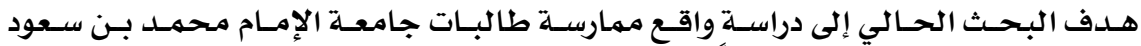

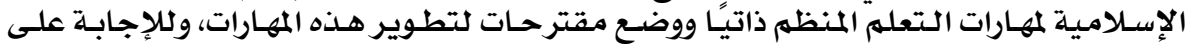

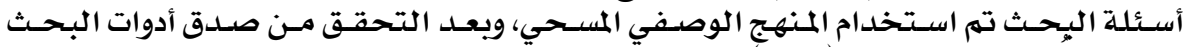

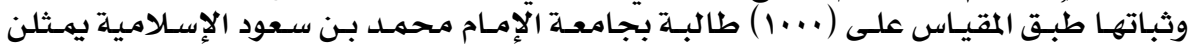

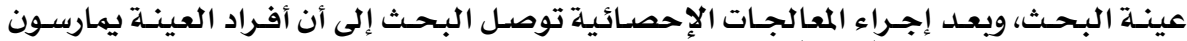

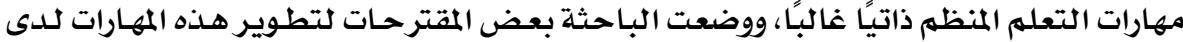

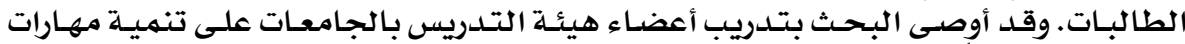

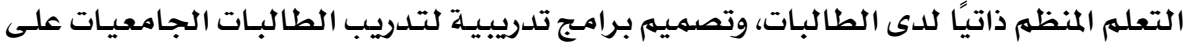

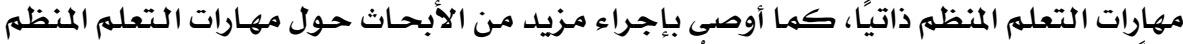

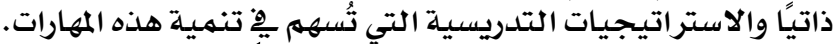

الكلمات المفتاحية: مهارات الاتئرات التعلم المنظم ذاتيًات

\section{The Reality Behind the Usage of Self-Organized Learning Among}

Female Students in Imam Muhammed Bin Saud University

Dr. Tahani Khalid Al-Jubair

\section{Abstract}

The main objective of this research is to study the reality behind the usage of self-organized learning among female students in Imam Muhammed bin Saud university and put suggestions to further develop these skills. In order to answer the questions of this research, the descriptive approach was used. After verifying the validity of the research tool, it was applied to (1000) female students representing the sample. After the statistical analysis, the research concluded that the participants often use the self-organized learning. The researcher put multiple suggestions to further develop these skills. The research recommends training the teaching faculty of universities in selforganized learning development for students and design programs to train the female university students develop these skills. Furthermore, the research suggests doing more research on the topic of selforganized learning and the teaching methods that contribute to the development of these skills.

Key word: self-organized learning skills

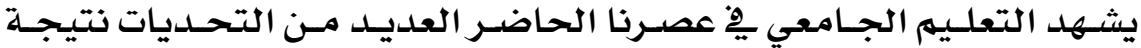

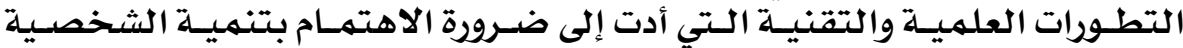

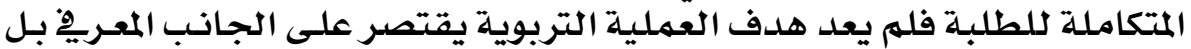

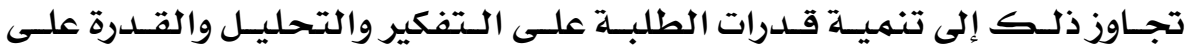
التعامل مـع المعلومـات والمعارف بكفاءة وفئه وفاعليـة. 
ويؤكد إيستيبـان وبيرت (Esteban\& Peart, 2014, p1) أن التغييرات التي

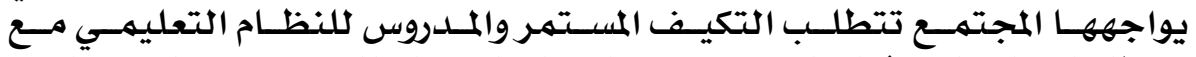

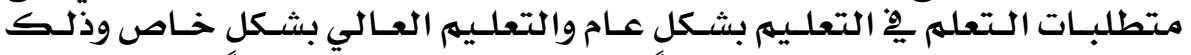

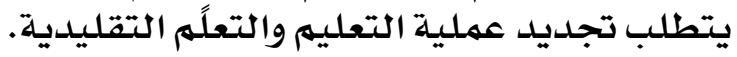

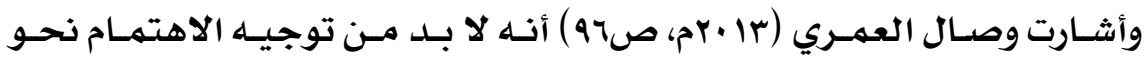

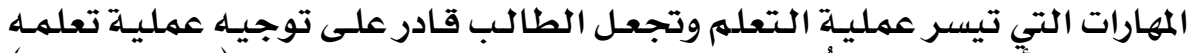

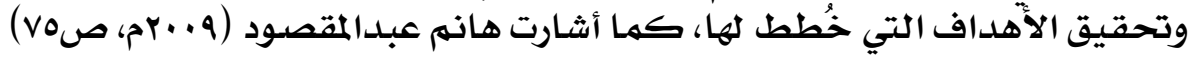

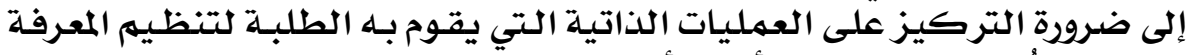

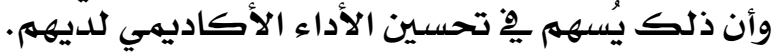

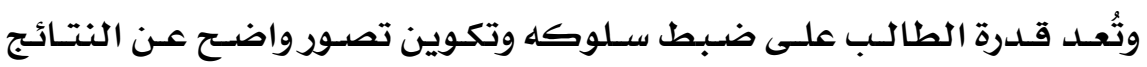

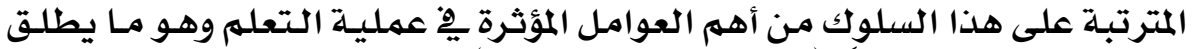

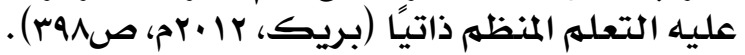

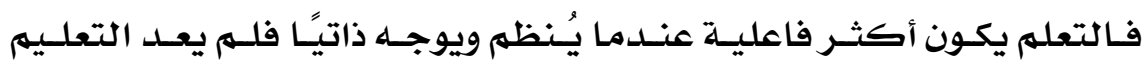

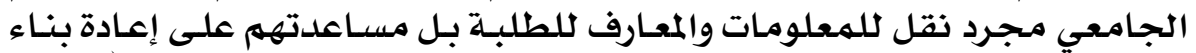

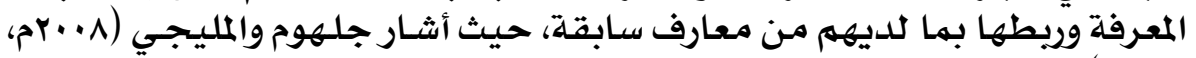

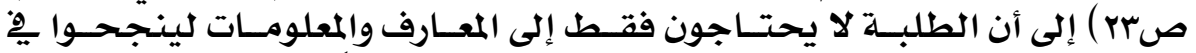

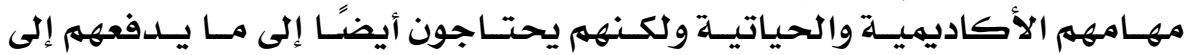

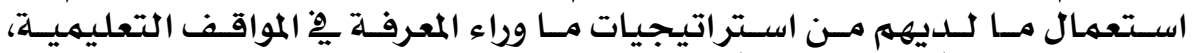

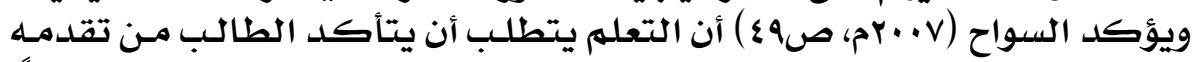

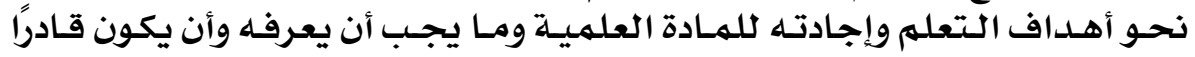

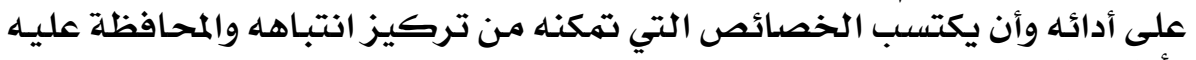
لأطول فترة مهكنة أنها

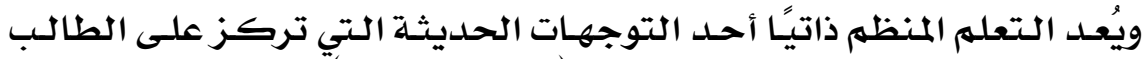

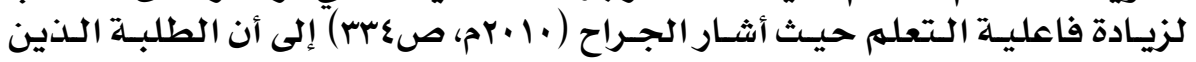

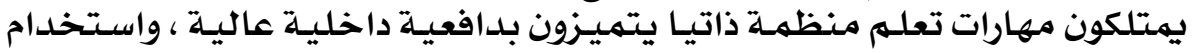

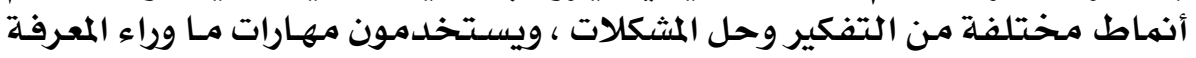

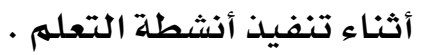

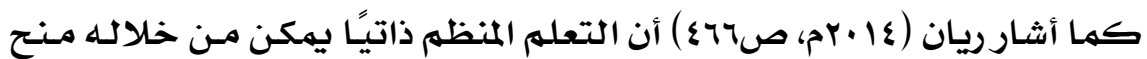

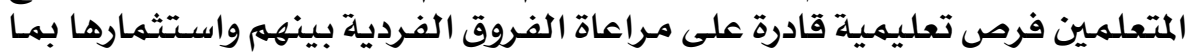

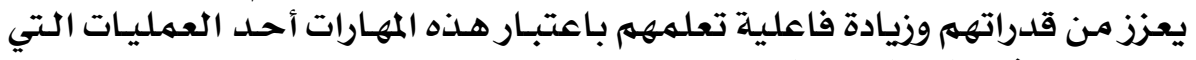

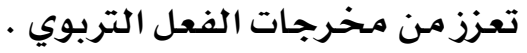

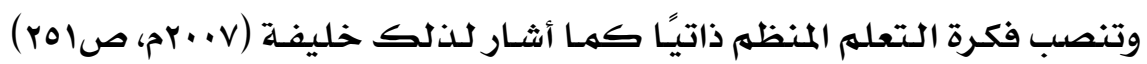

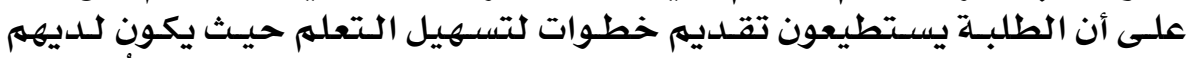

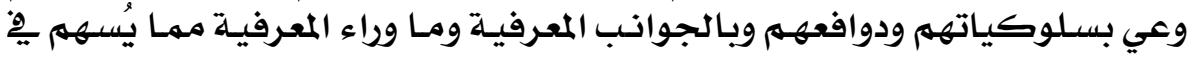




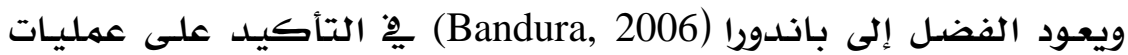

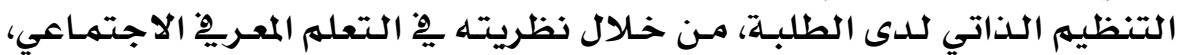

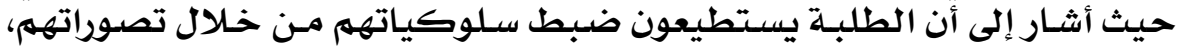

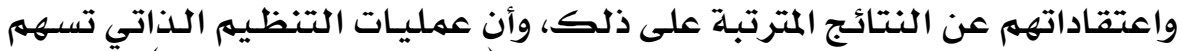

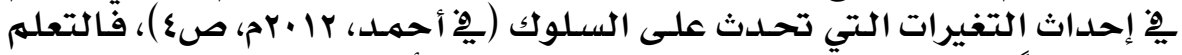

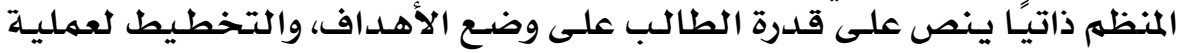

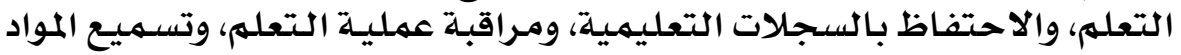

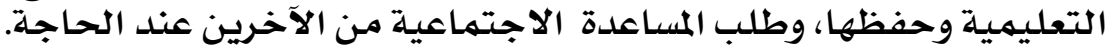

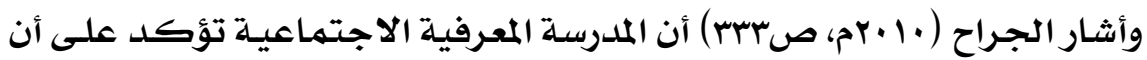

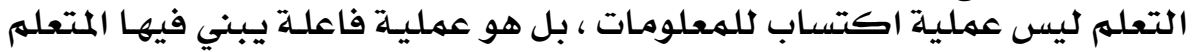

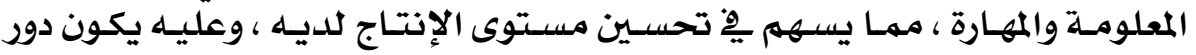

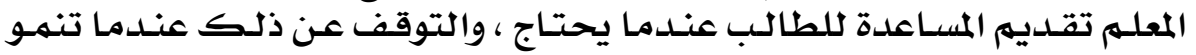

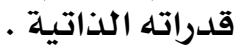

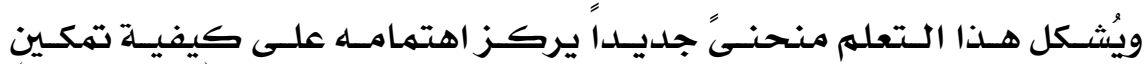

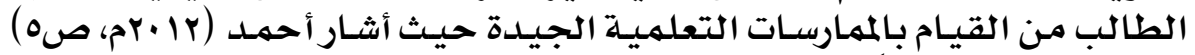

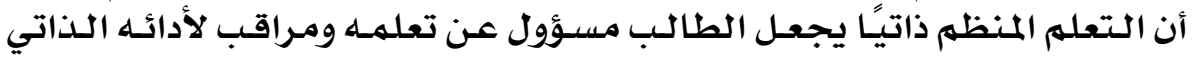

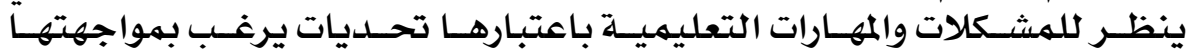

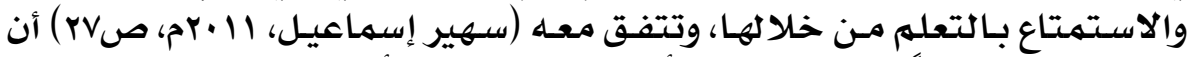

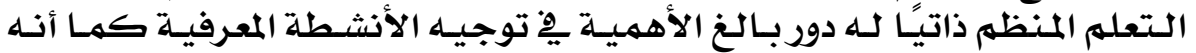

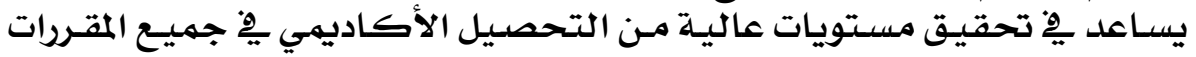

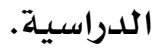

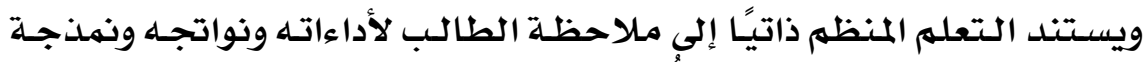

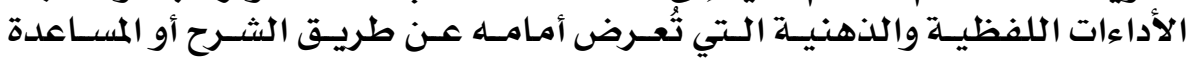

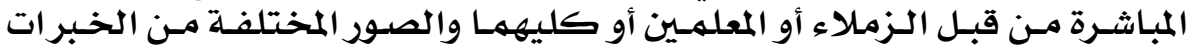

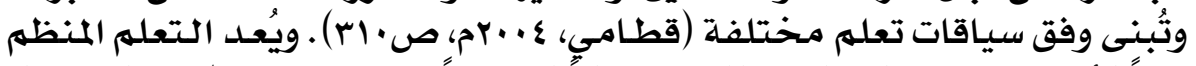

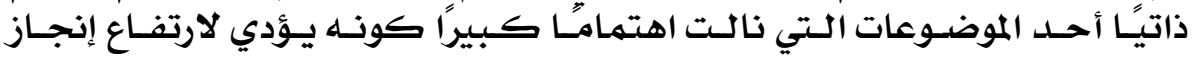

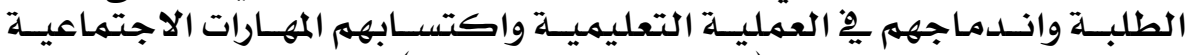

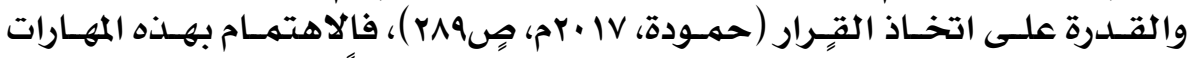

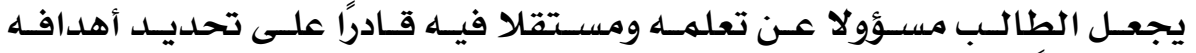

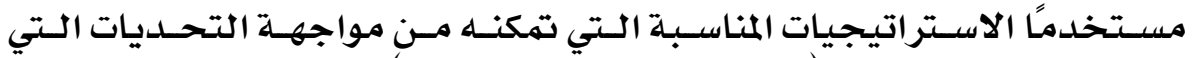

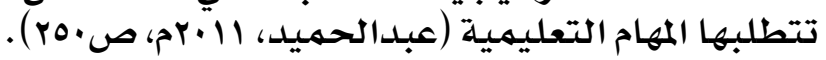

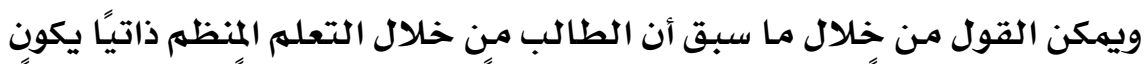

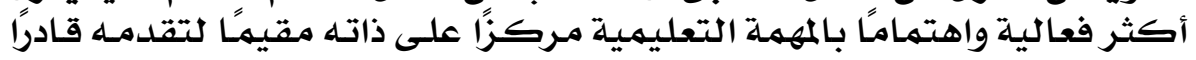

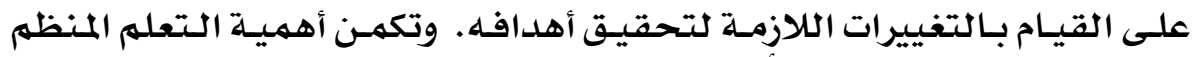

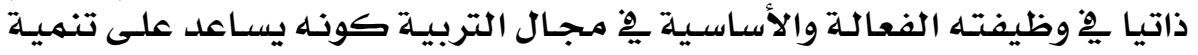




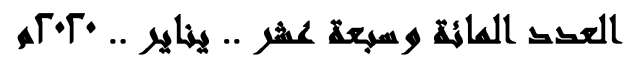

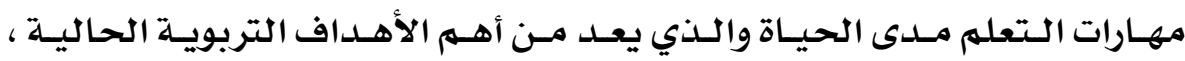

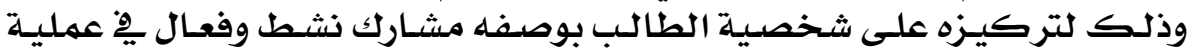

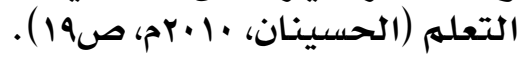

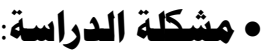

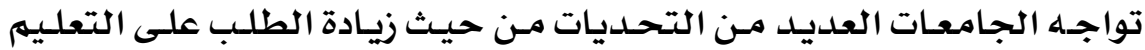

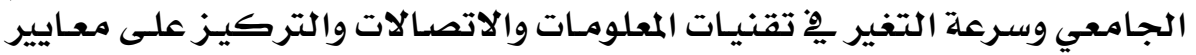

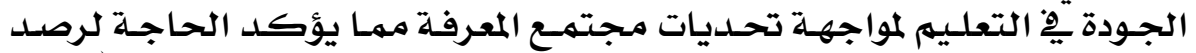

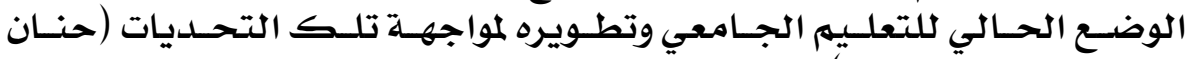

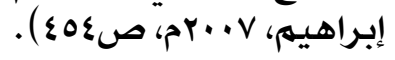

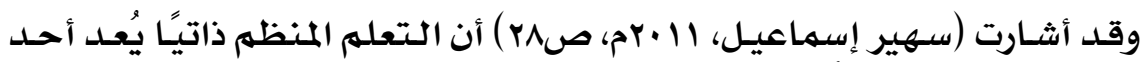

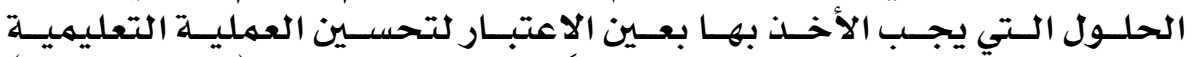

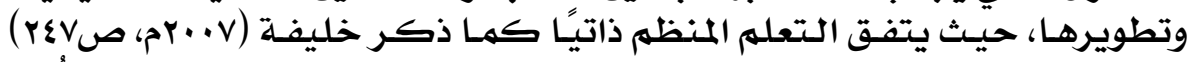

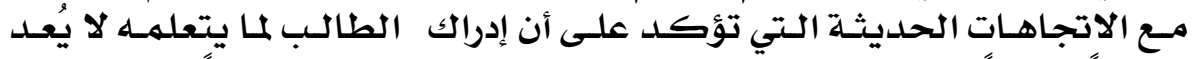

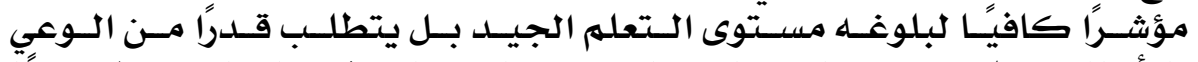

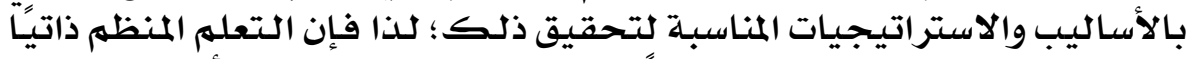

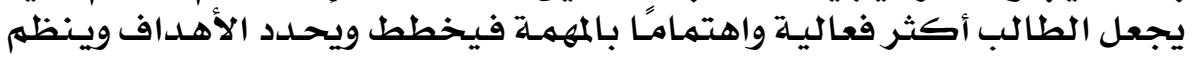

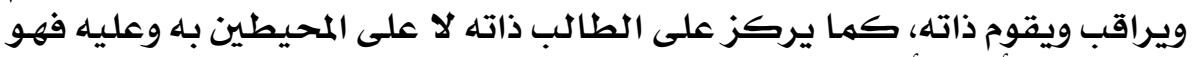

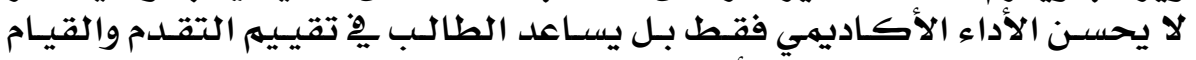

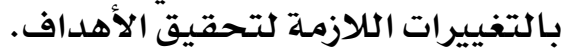

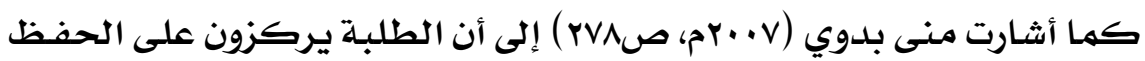

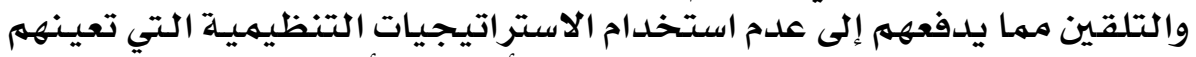

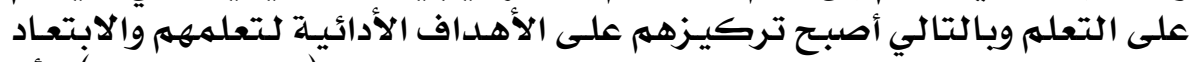

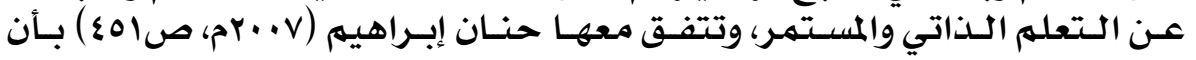

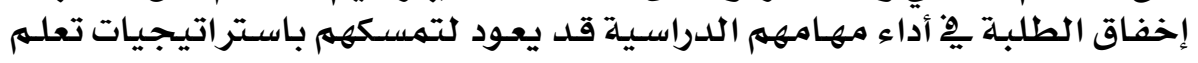

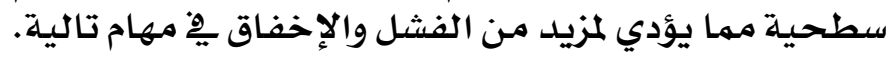

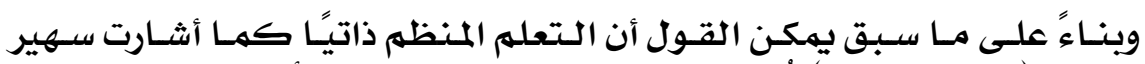

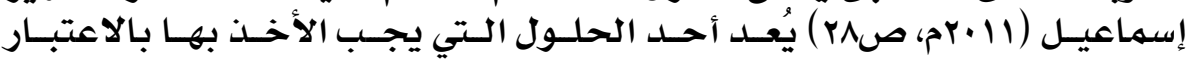

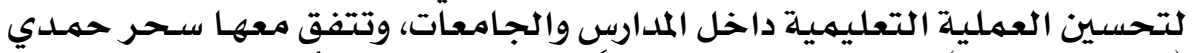

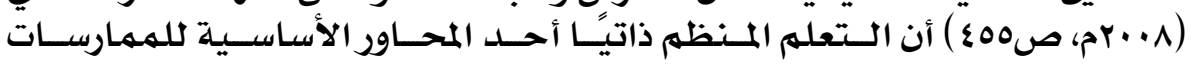

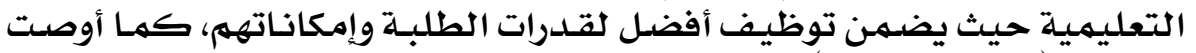

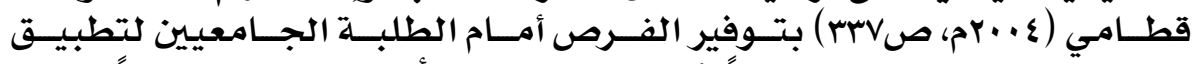

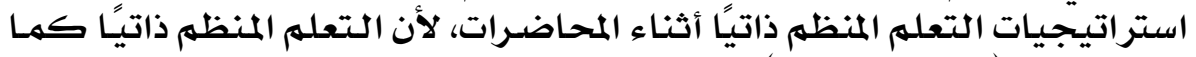

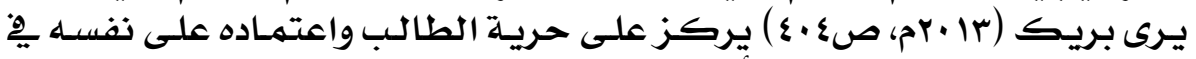

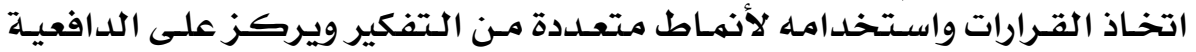

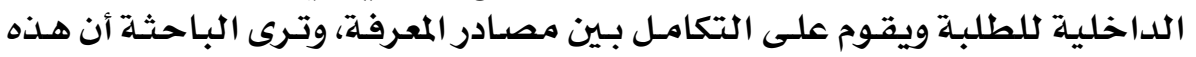

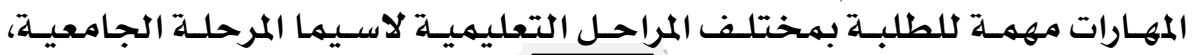

\section{$10 \varepsilon$}




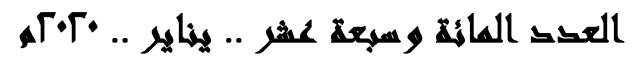

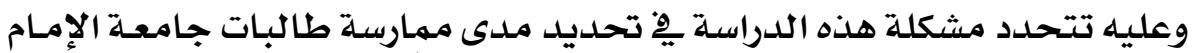

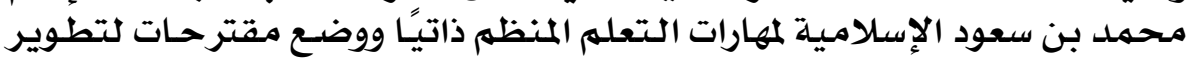

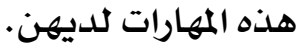

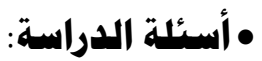

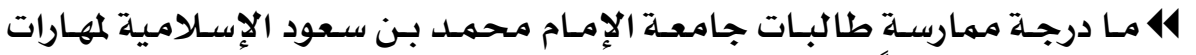

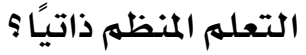

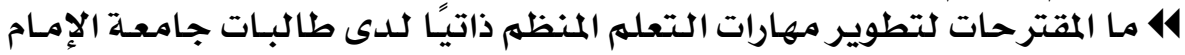

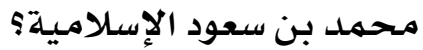
•أهداف الدراسة: 44 الكثف عن درجـة مهـارسـة طالبـات جامعــة الإمـام محمهـد بـن سعود الإسـلاميلة لمهارات التعلهم المنظم ذاتش داتيًا.

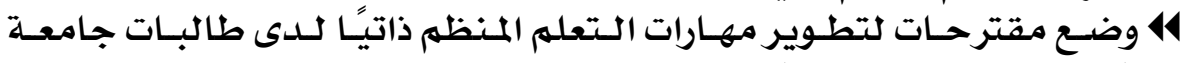
الإمام محممد بن سعود الإسـلاميلة. • أهسمية الدراسة ماسة:

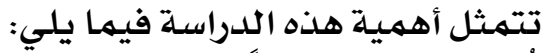

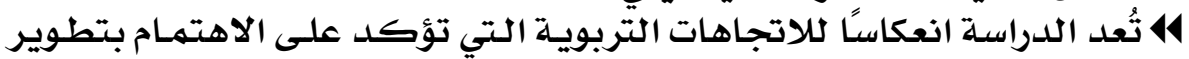

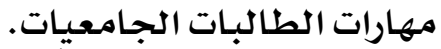

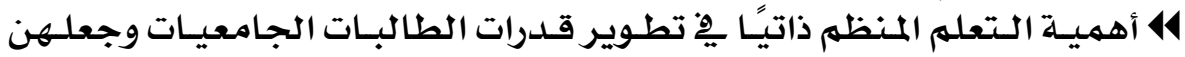

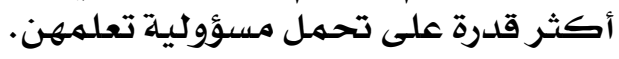

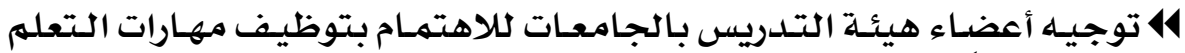

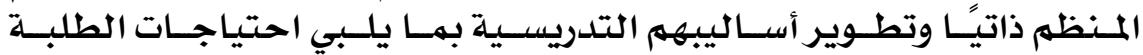
الجامعيين.

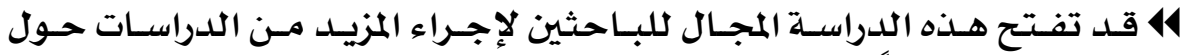

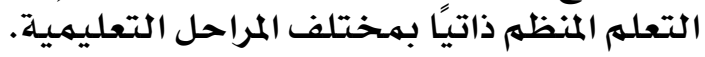

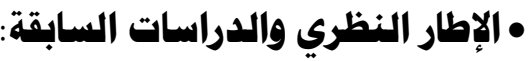

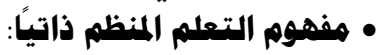

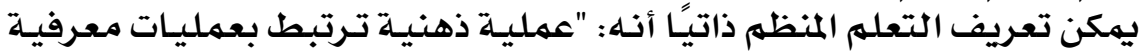

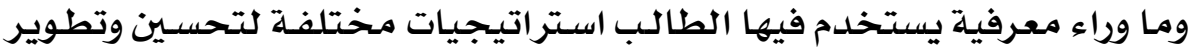

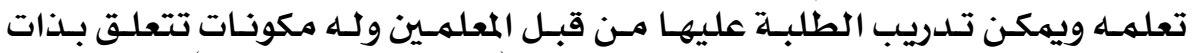

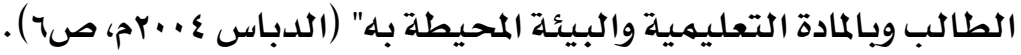

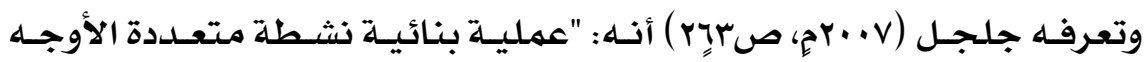

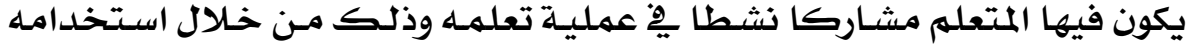

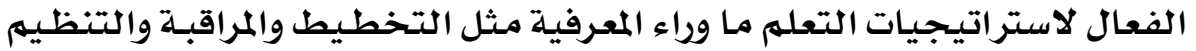

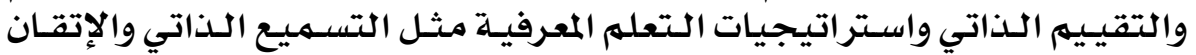

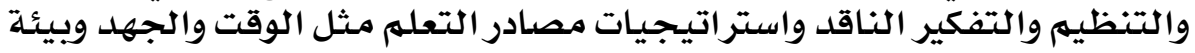

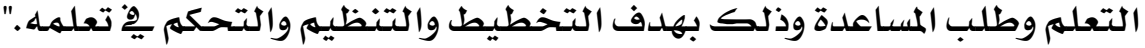

\section{0}




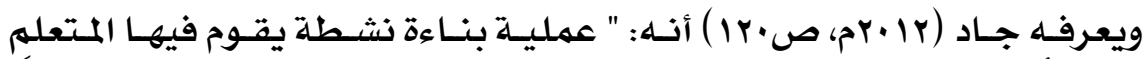

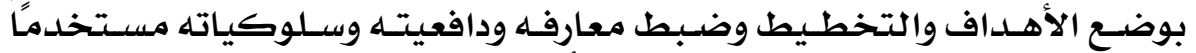

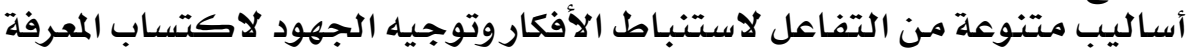

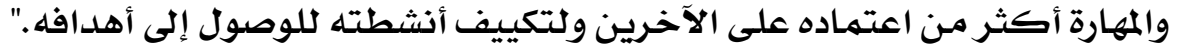

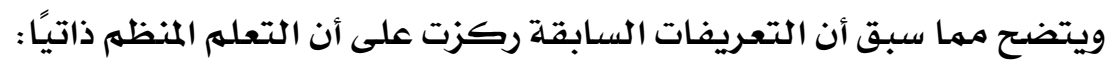
14 عملية بنائية نشطة.

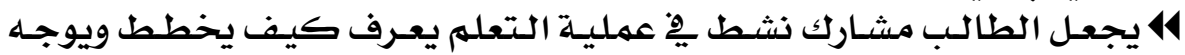

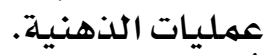
11 يُكسب الطالب الاستراتية التيجيات المعرفية وما وراء المعرفية وكيفية استخدامها

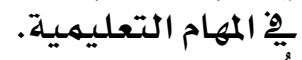
14 يُكسب المهام التعليمية القدرة على مواجهة الصعوبات التي تواجهه أثناء التعله. • أسس التعلم المنظم ذاتيا:

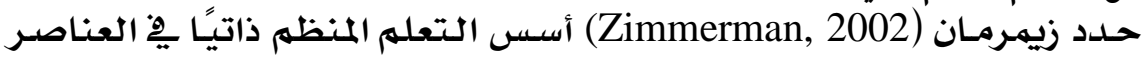
التتادية: احسية

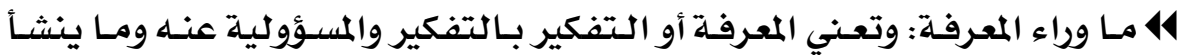

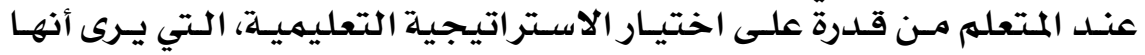

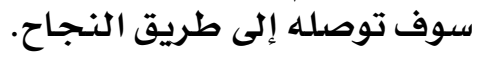

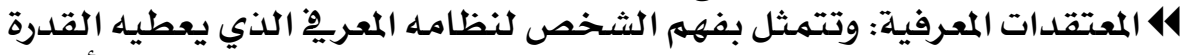

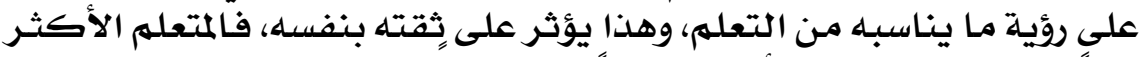

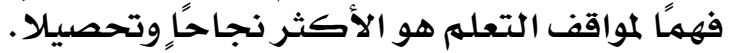

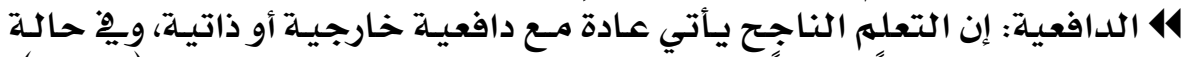

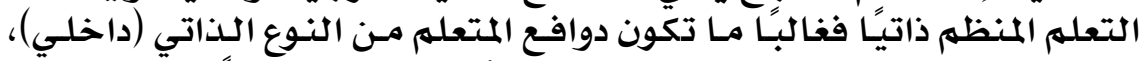

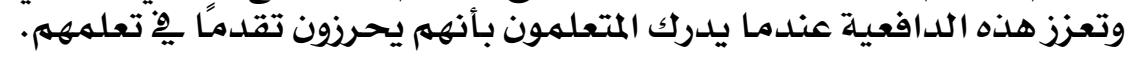

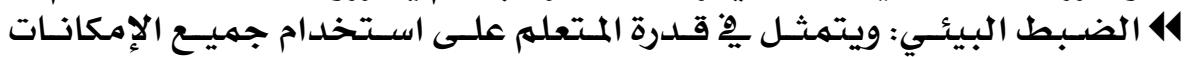

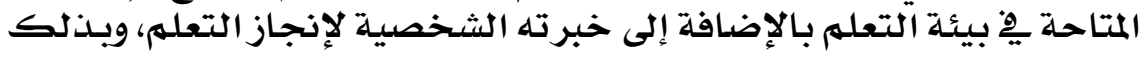

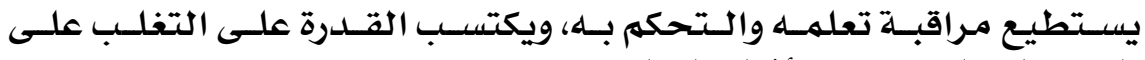

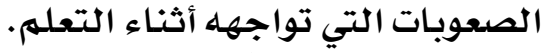

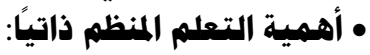

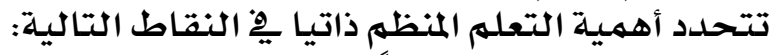

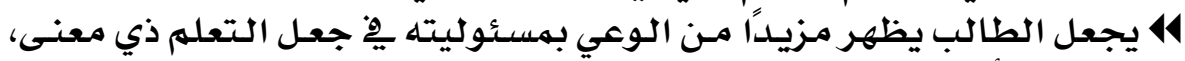
ومـراقب لأدائه الذاتي.

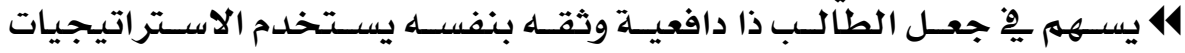
المختلفة؛ لتحقيق أهداف الهـاف التعله.

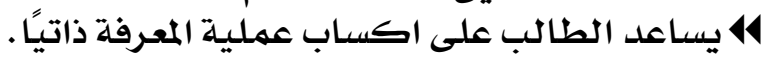

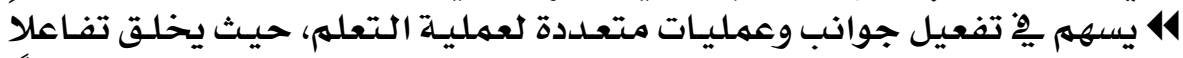

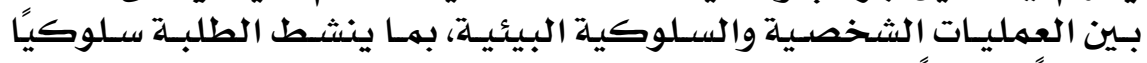
ومعرفيًا ودافعيًا. 


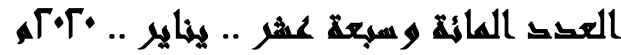

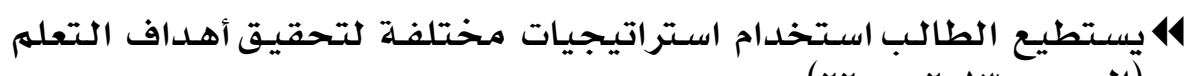

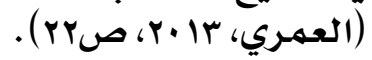

وأضاف نيلسون (Nilson, 2013, p16):

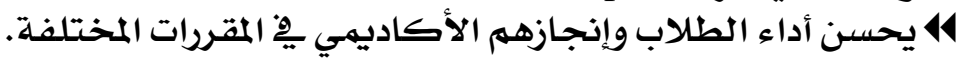

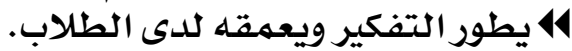

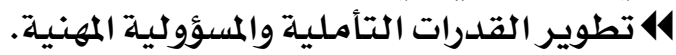

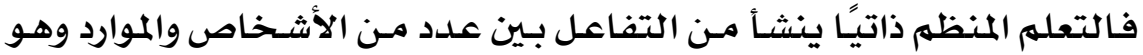

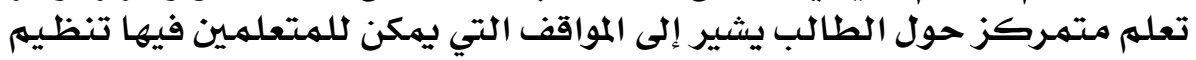

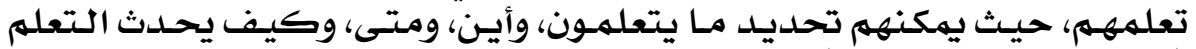
(In Ricci, 2011, p138)

• استراتيجيات التعلم المنظم ذاتيًا:

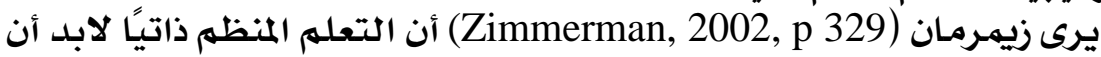
يتضمن تعلهم الطلاب استخدان (اسم استراتيجيات محلددة وهي:

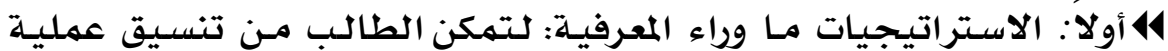

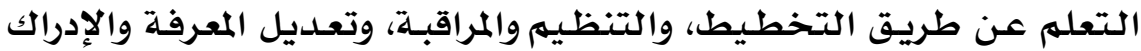

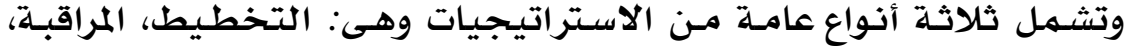

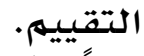

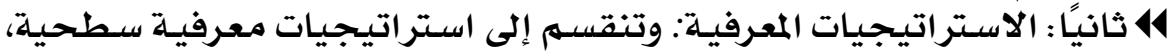

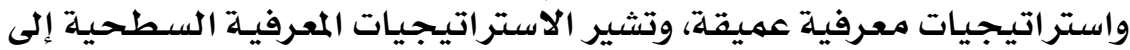

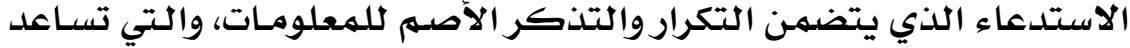

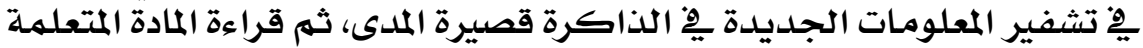

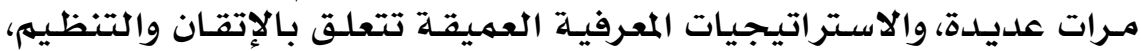

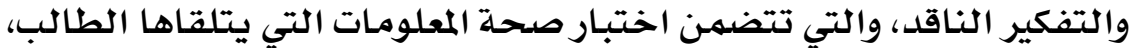

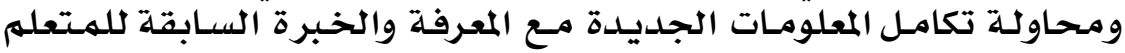

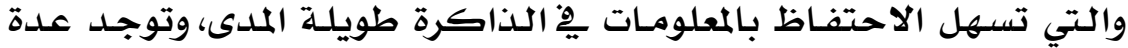

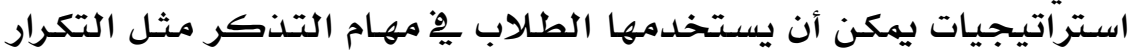

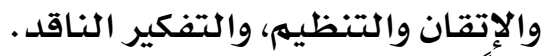

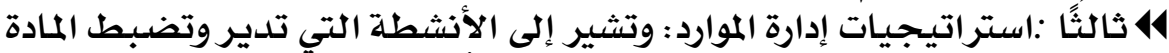

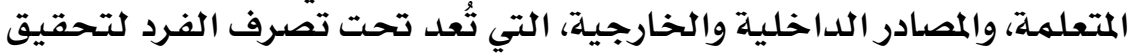

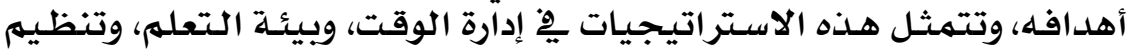

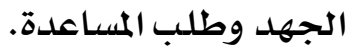
• الدراسات السابقة:

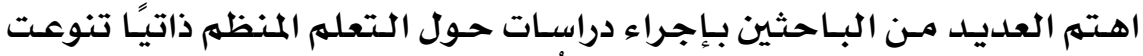

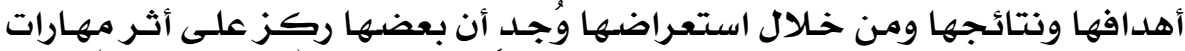

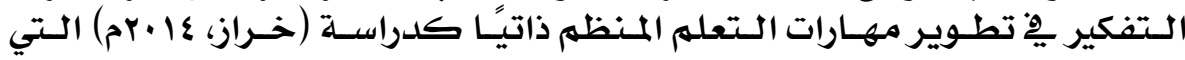




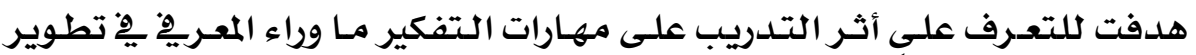

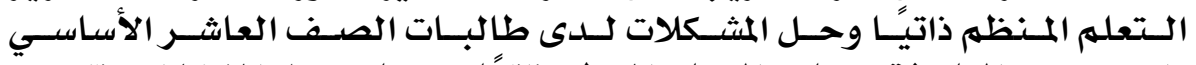

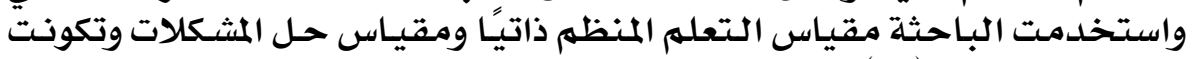

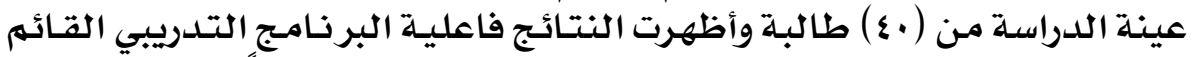

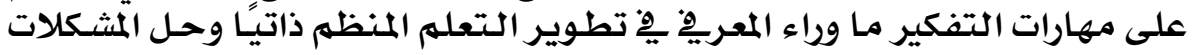
لدى عينة الدراسلة.

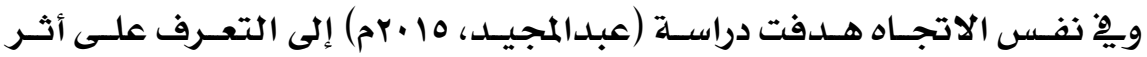

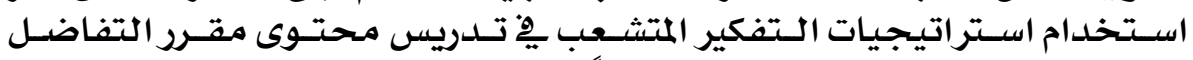

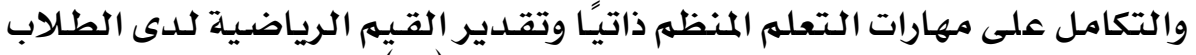

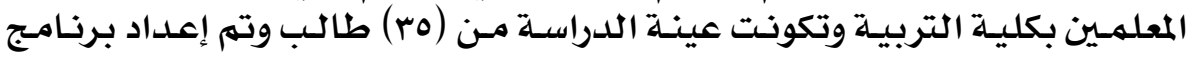

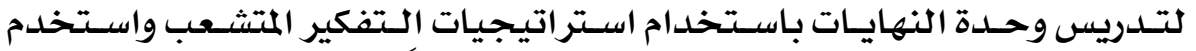

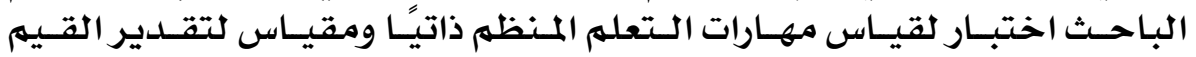

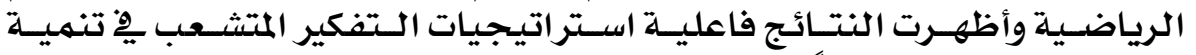

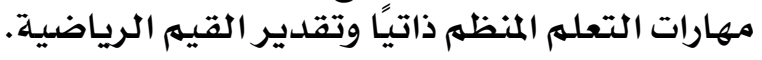

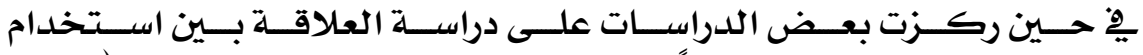

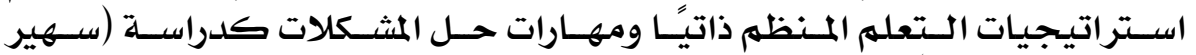

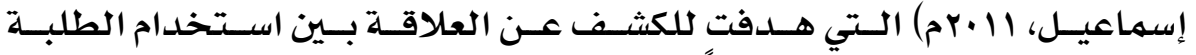

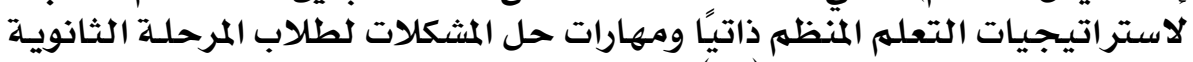

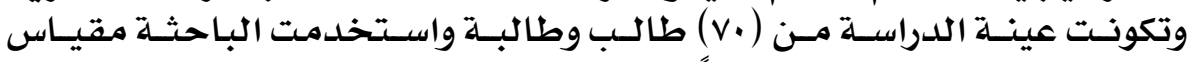

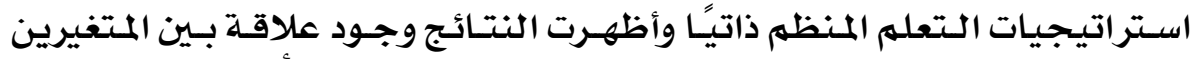

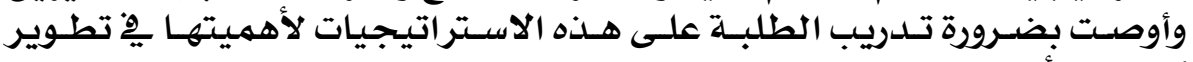

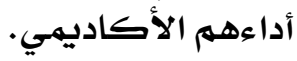

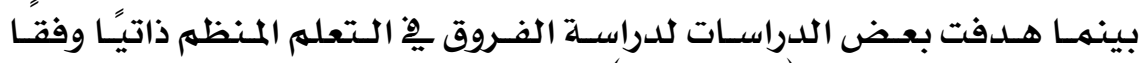

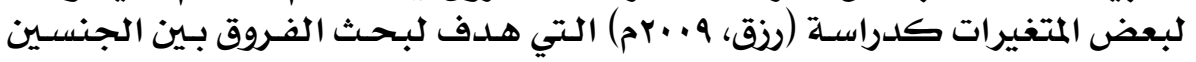

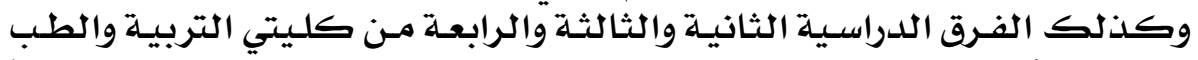

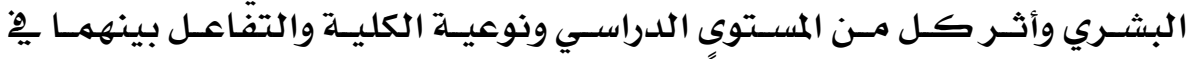

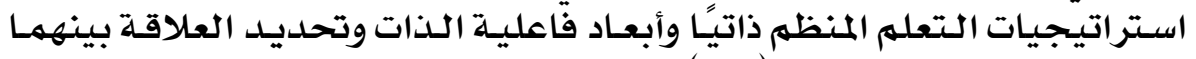

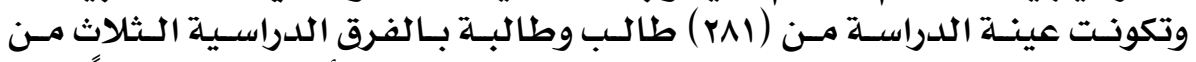

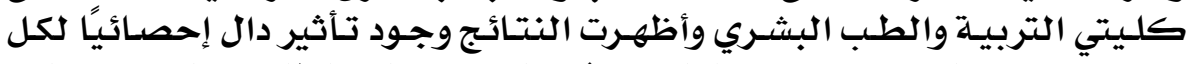

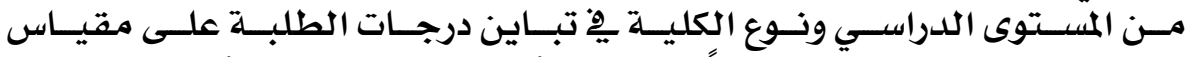

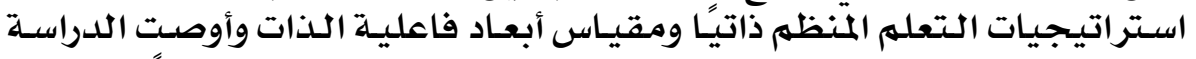

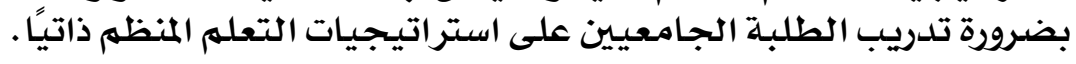

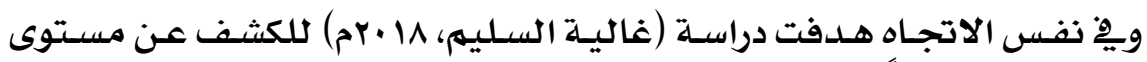

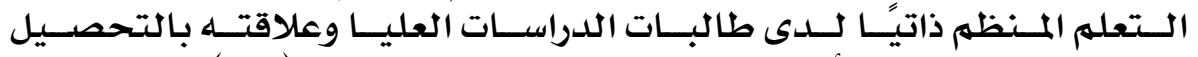

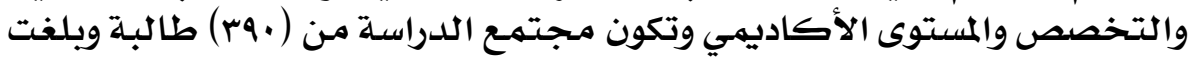




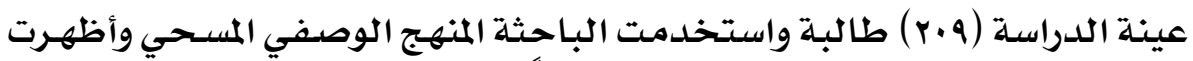

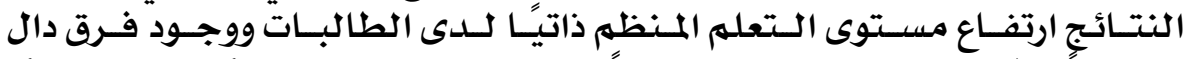

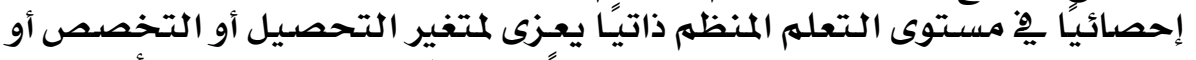

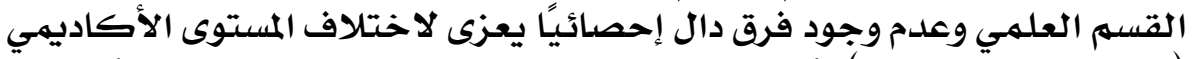

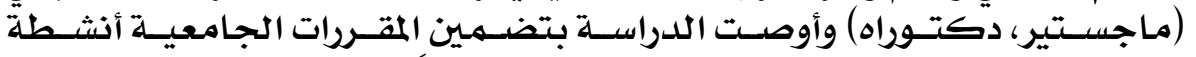

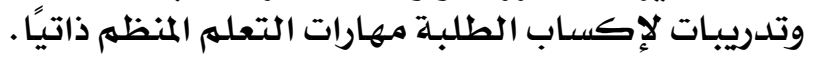

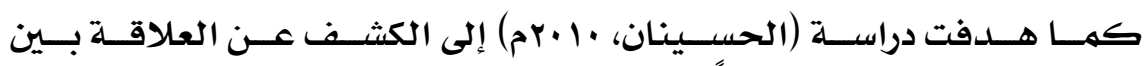

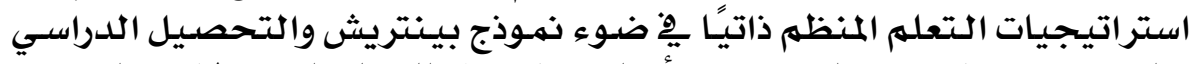

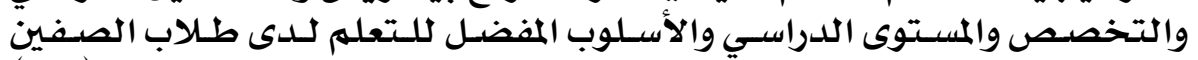

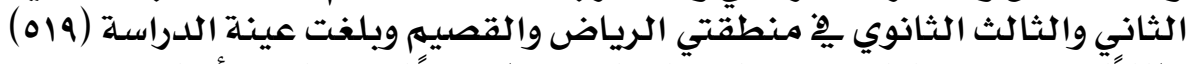

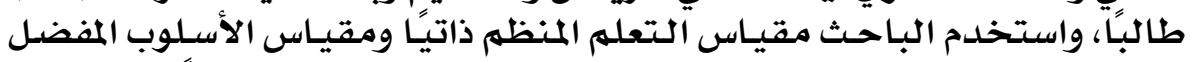

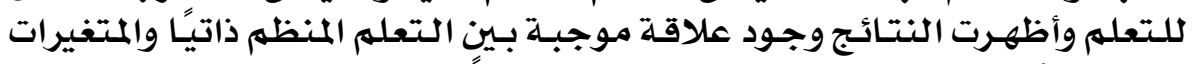

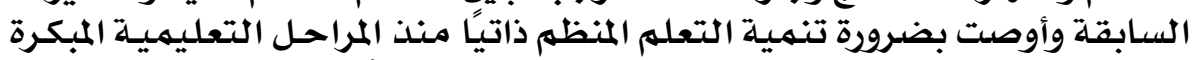

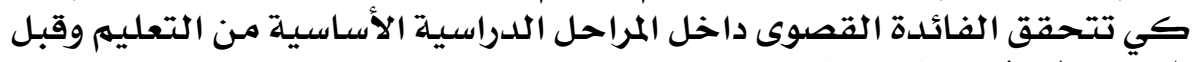

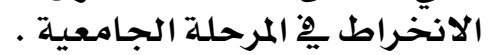

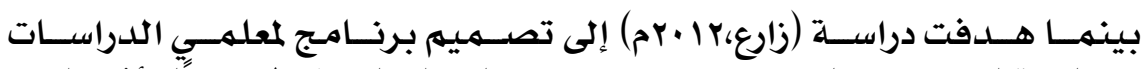

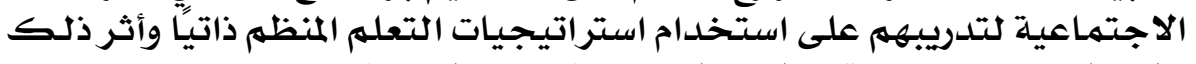

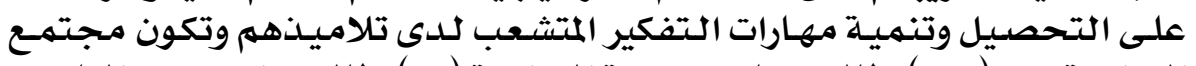

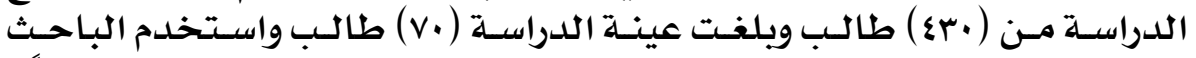

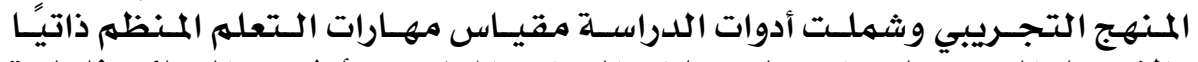

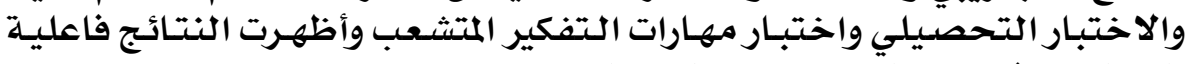

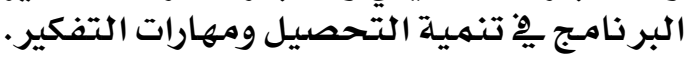

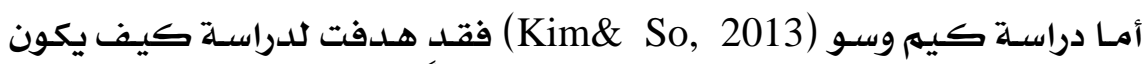

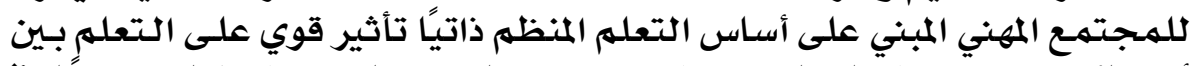

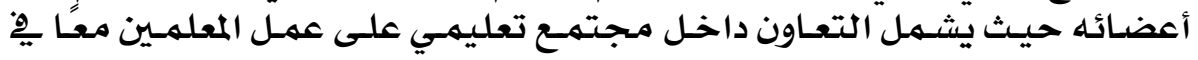

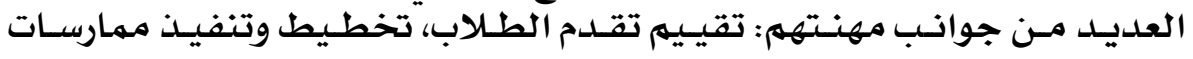

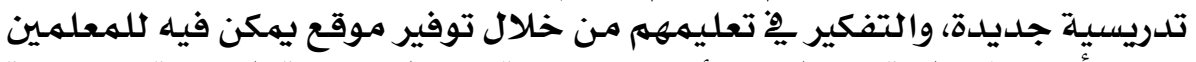

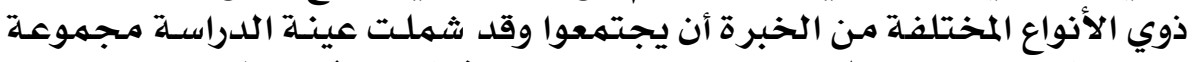

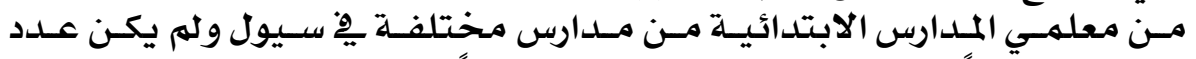

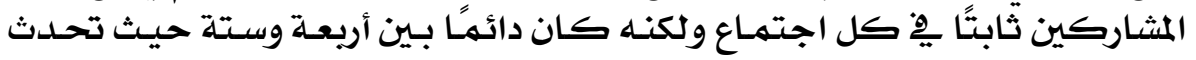

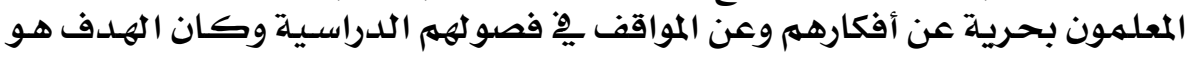

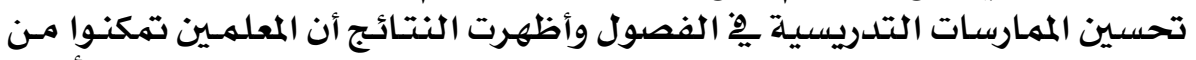

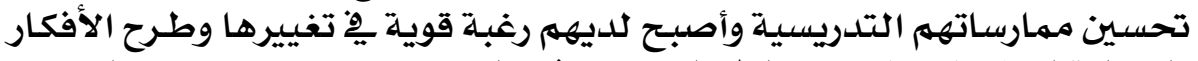

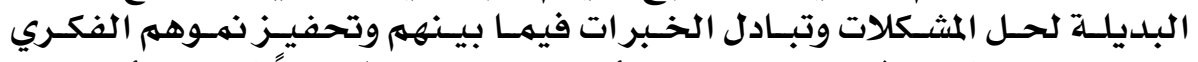

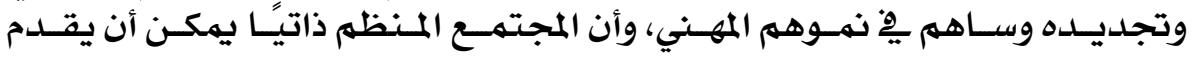




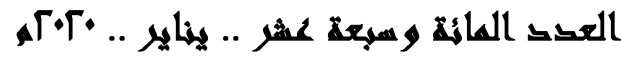

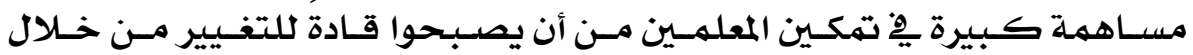

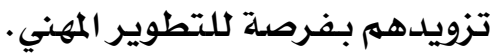

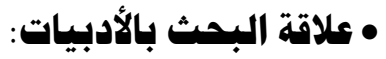

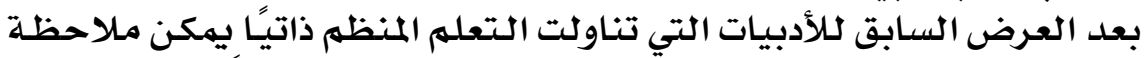

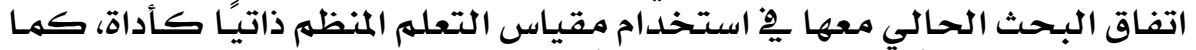

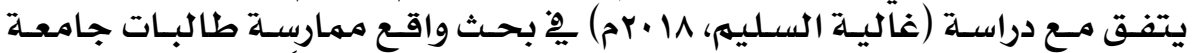

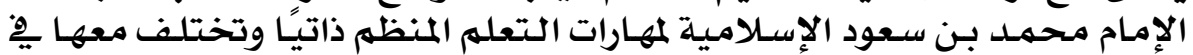

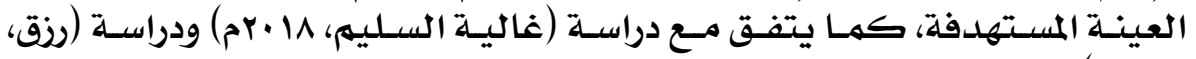

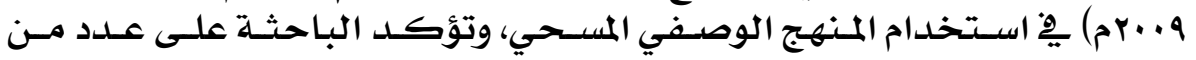

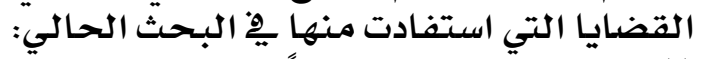

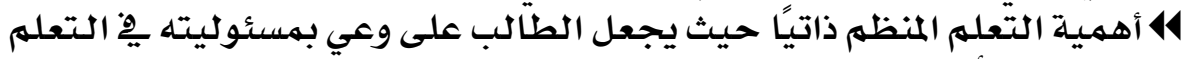

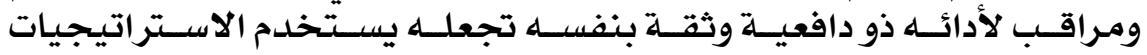

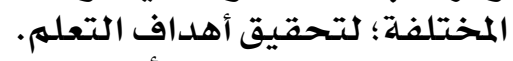

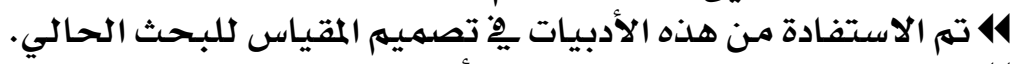

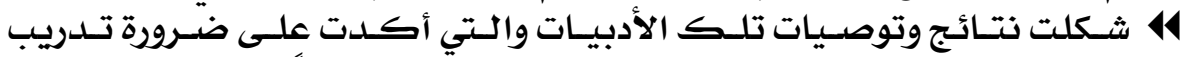

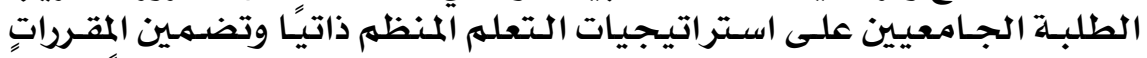

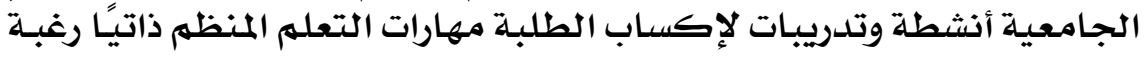

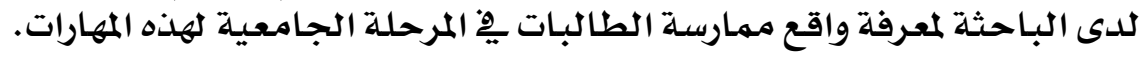

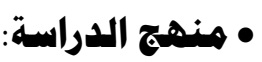
من أجل تحقيق أهداف الدراسة استخدمت الدياحثة المنهـج الوصفي المستحي.

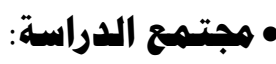

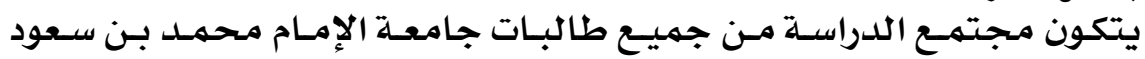

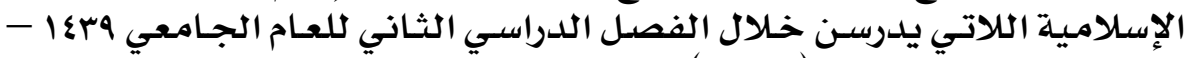

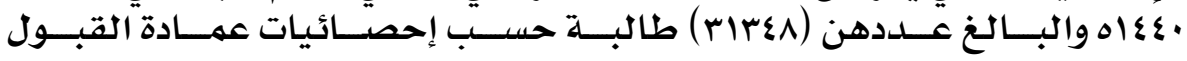
والتسجيل.

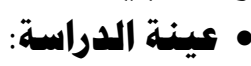

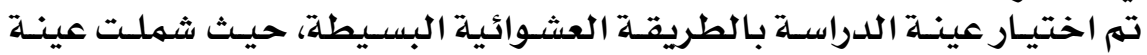

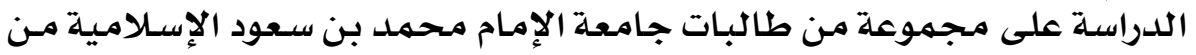

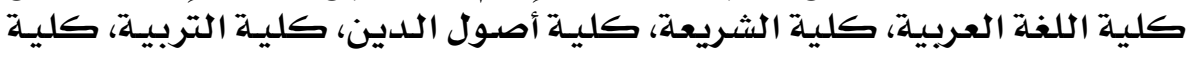

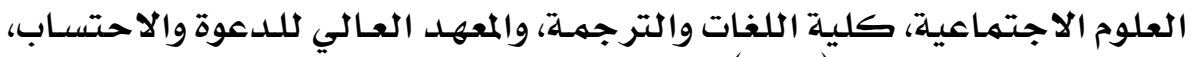

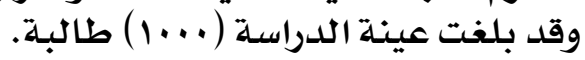

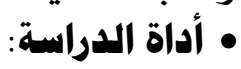

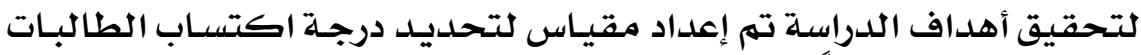

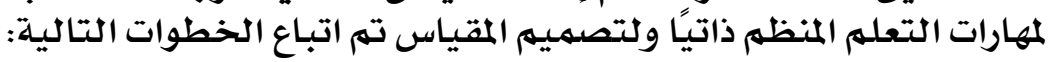

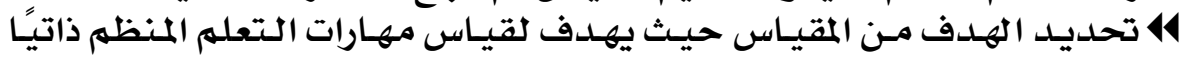

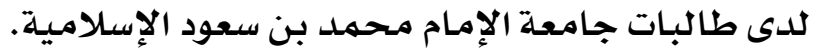

\section{4.}




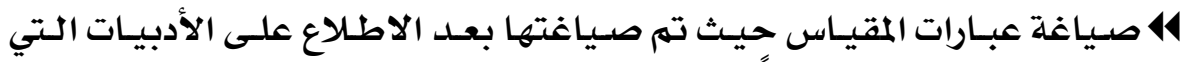

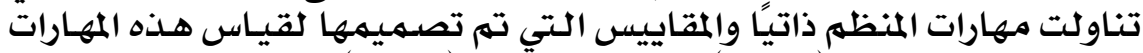

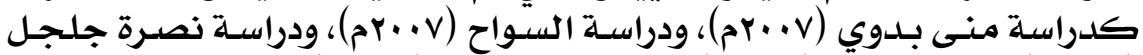

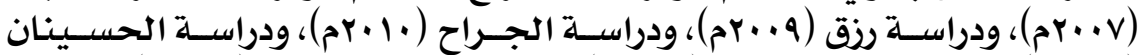

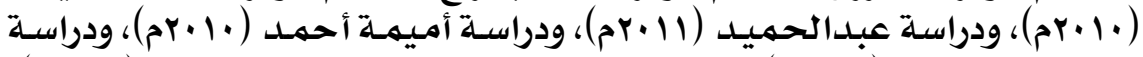

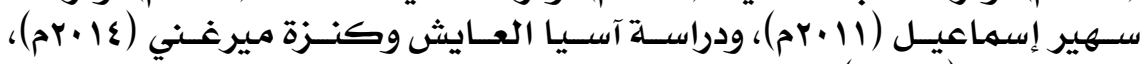

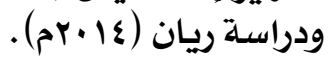

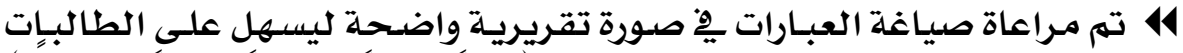

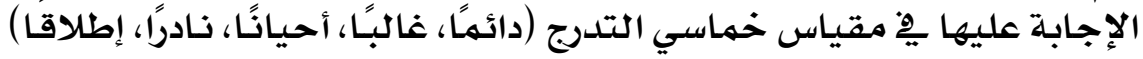

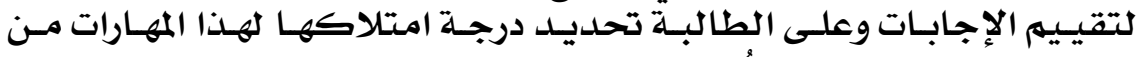

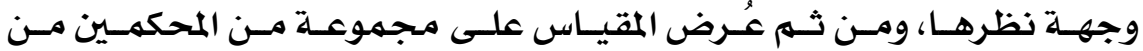

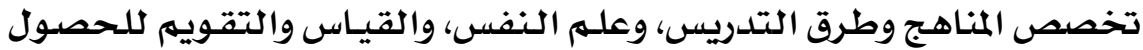

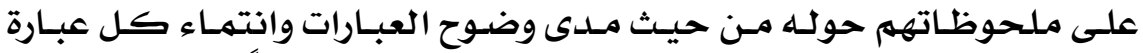

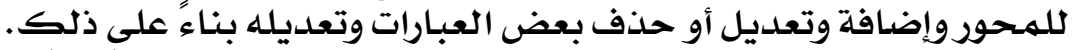

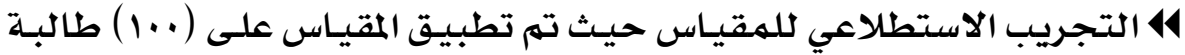

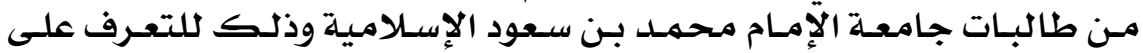

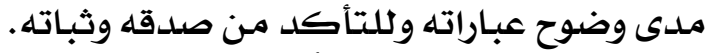

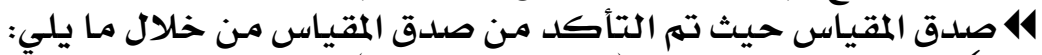

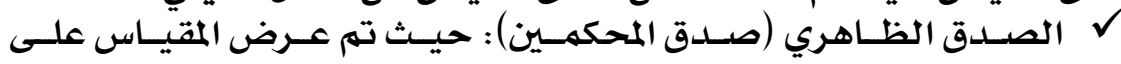

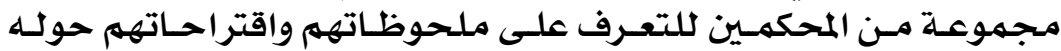

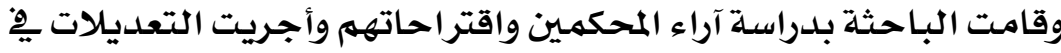
ضوء ذلك.

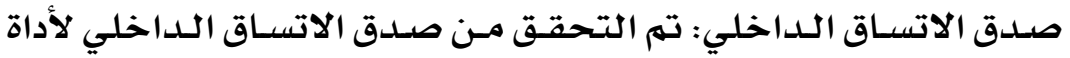

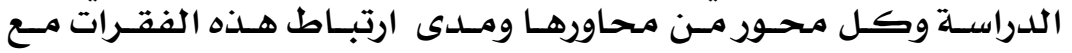

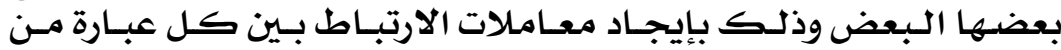

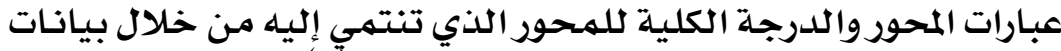

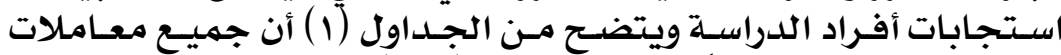

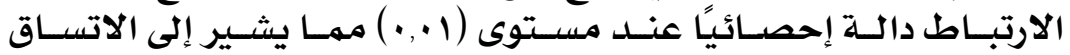

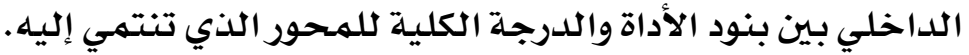

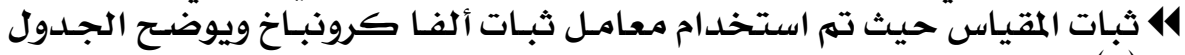

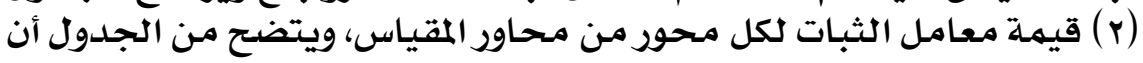

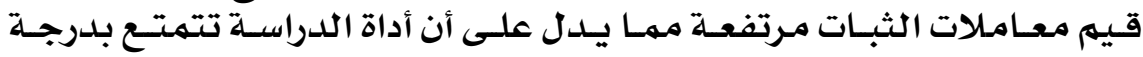
عالية من الثبات.

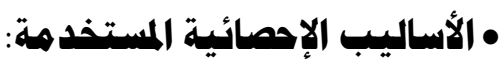

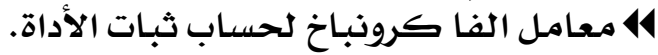

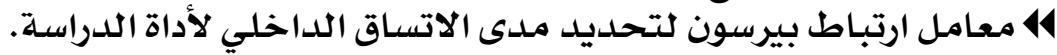

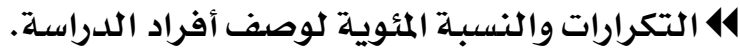

\section{1}


جدول (1) معاملات الارتباط لكل عبارة من عبارات المحور بالدرجت الكليت للمحور الذي تنتمي إليه

\begin{tabular}{|c|c|c|}
\hline 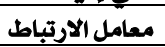 & |لعبارة & م \\
\hline - ,org & اضضع لنفسي معيارًا لأدئي على تكليفات المقررات التي أدرسها واجتهد في أوصول إليه & 1 \\
\hline ه.,orr & 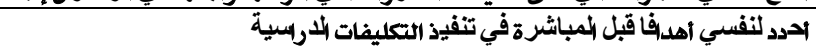 & $r$ \\
\hline$\leftrightarrow 4,711$ & وحافظ على دوفية عالية وثاء دربستي للمقررات الثربسية. & $r$ \\
\hline$\leftrightarrow,+, \cdot 1$ & تقوم بإعداد جدول زمني للدربة. & $\varepsilon$ \\
\hline$\leftrightarrow \leftrightarrow, 0 \wedge$. & احرص على اشتثمار الوقت في متابعت تكليفاتى الدربسية باتتظام. & 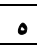 \\
\hline ४4,orr & اخصص لنفسي مكاتًا مريحا للدراستة & 7 \\
\hline$\leftrightarrow, 0.9$ & اشعى للحد من مصادر التشتت التي قد تواجهني أثناء الدربة. & $\checkmark$ \\
\hline \$, orv & احرص على تلدوين الملاحظات المهمت أشناء الدراستة. & $\wedge$ \\
\hline$\leftrightarrow, 07$. & أطرح الأسئلت حول الموضوعات التي أجدصعوبة في فهمها. & 9 \\
\hline$\rightarrow 4,7.8$ & اخصص وقتا إضافيًا للمقررات التي اشعر بأنها أصعب من غيرها. & 1. \\
\hline ه , \&Ar & توجه بطلب المساعدة من زميلاتى في فهم النقاط الغامضت. & 11 \\
\hline$\leftrightarrow, 007$ & اعمل على إعداد ملخصات للمقزرات التي أدرسها. & ir \\
\hline$\leftrightarrow 4$, TYq & وحرص على طلب المساعدة من أستاذة المقرر إذا لزم الأمر عبر وسائل متعددة. & ir \\
\hline$\Delta \cdot, 7, Y$ & اوجه لنفسي أسئلة ذاتية لتقويم تعلمي لكل موضوع أدرسه. & is \\
\hline$\$ 4,707$ & السعى للحصول على تغلية رجعة حول مستوى أدئي في الاختبارات والتكليفات. & 10 \\
\hline$\Delta \cdot, \mathrm{TVR}$ & وحرص على دربسة المقررات الدربسية اولابأول. & 17 \\
\hline$\leftrightarrow 4,097$ & اضغع أفكالأ مبسطت ورسومًا بيانيت وجداول لتساعدنى على تنظيم المقرر بصورة أفضل. & IV \\
\hline$\leftrightarrow \cdot \mathrm{V}$. & اوحرص على تطوير مهارئي الدراسيتباستمرار مستقيدةً من خبرات الآخرين. & M \\
\hline$\Delta \sim, \triangle \wedge \varepsilon$ & أثناء الدراست اتصفح القراءات والملخصات وأحاول الحصول على أهم الأفكار. & 19 \\
\hline$\leftrightarrow \bullet$, Tะ9 & احرص على الاستفادة من جميع مصادر التعلم المتاحة لي. & r. \\
\hline$\leftrightarrow$,OYI & غالبًا أفكر فيما أسمعه أو آقراه لأقرر إذا ما كان مقنعًا أم لا. & M \\
\hline ه.,orr & عندما تكون المعلومت غير واضحت فإننى أعود واحاول أن أفهمها مرة نانيت. & rr \\
\hline$\leftrightarrow 4,7+0$ & اخصص وقت لمناقشت المقرر الدراسى مع مجموعت من الزميلات. & rr \\
\hline$\Delta$, oru & عندما أستذكر دروسى فإننى أجمع المعلومات من مصادر مختلفتة. & YE \\
\hline$\leftrightarrow, 0 \varepsilon \varepsilon$ & احاول ربط الأفكارِّ2 موضوع ما بالأفكار ِِ2 مقررات دراسيت اخرى كلما أمكن ذلك. & ro \\
\hline
\end{tabular}

جلول (r) قيم معاملات الثبات لكل محور من محاور الاستبانت

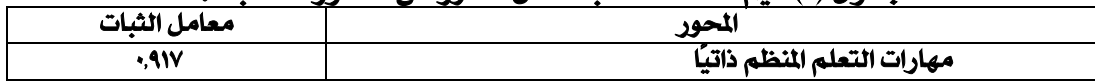

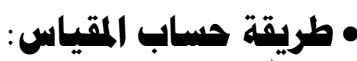

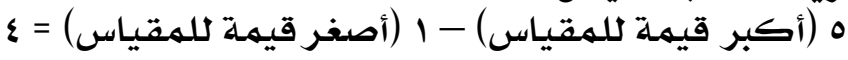

$$
\begin{aligned}
& \cdot, \Lambda \cdot=0 / \varepsilon \\
& 1, \Lambda \cdot=1+\cdot, \lambda \cdot \\
& \text { Y, т. }=\cdot, \Lambda \cdot+1, \Lambda \cdot \\
& r, \xi \cdot=\cdot \lambda \cdot+r, \boldsymbol{r} \cdot \\
& \varepsilon, Y \cdot=\cdot, \Lambda \cdot+r, \xi \cdot \\
& 0=\cdot, \Lambda \cdot+\boldsymbol{\varepsilon}, \boldsymbol{r} \text {. }
\end{aligned}
$$




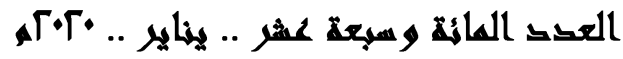

\begin{tabular}{|c|c|}
\hline درجت الممارستة & المتوسط \\
\hline مائمًاً & $0-\varepsilon, Y I$ \\
\hline غالبًا & $\varepsilon, r \cdot-r, \varepsilon)$ \\
\hline أحيانًا & $\left.r, \varepsilon_{*}-r, 7\right)$ \\
\hline نادراً. & $r, 7 \cdot-1, \wedge 1$ \\
\hline إطلاقا & $1,1 \cdot-1$ \\
\hline
\end{tabular}

\begin{tabular}{|c|c|c|c|c|c|}
\hline إطلاقا & ثادرا & أحيانًا & غالبًا & دائمًا & درجت الممارست \\
\hline 1 & $r$ & $r$ & $\varepsilon$ & 0 & الوزن \\
\hline
\end{tabular}

\section{• نتائج الدراسة:}

• الإجابة على السؤال الأول: مها واتع مهارسة طالبات جامعة الإهام هممد بـن سـعود الإسـلاهية المهارات التعلم المنظم ذاتياً المانه

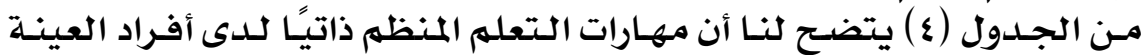
تترتب وفق التتالي:

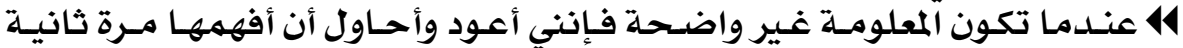

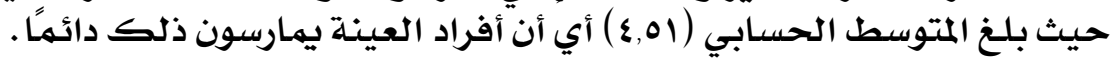

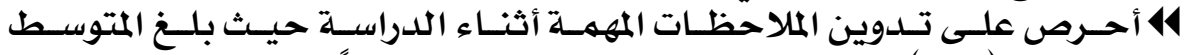

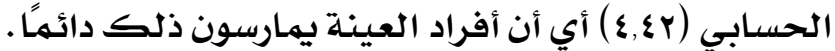

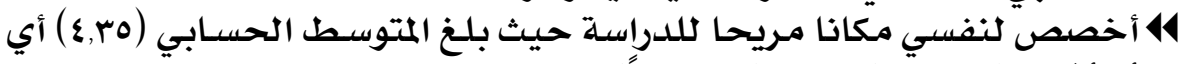

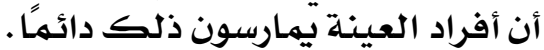

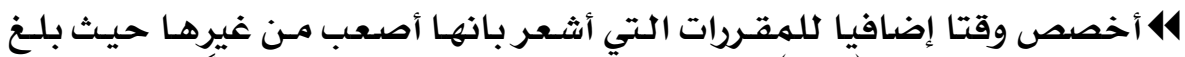

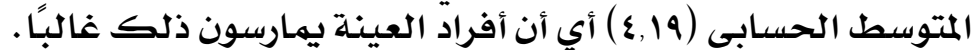

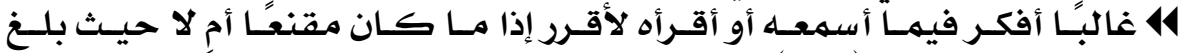

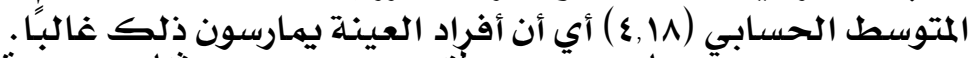

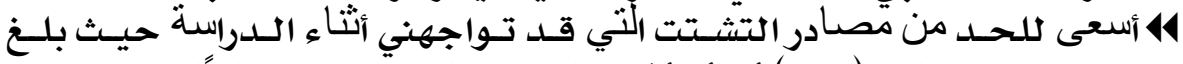

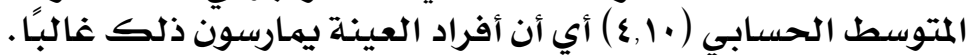

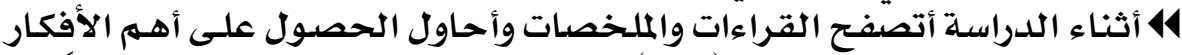

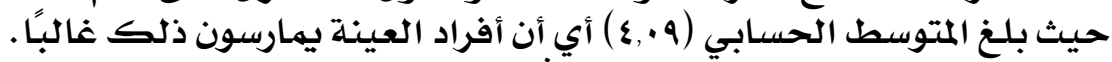

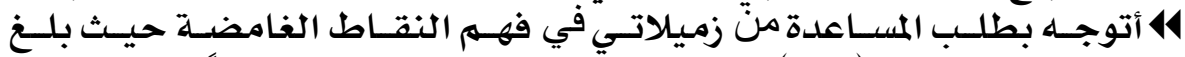

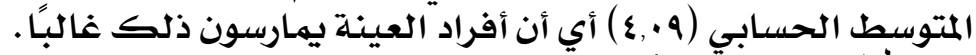

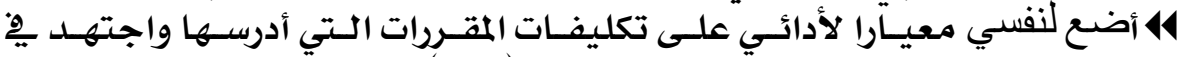

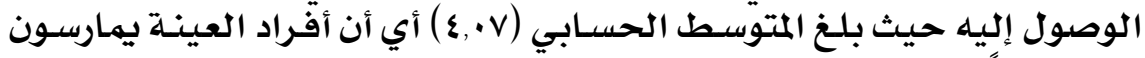
ذلك غالبًا.

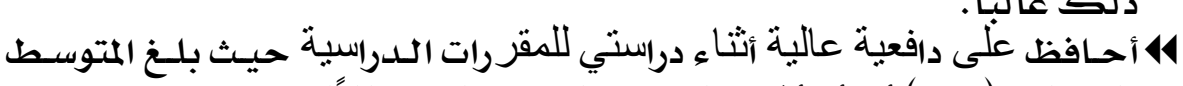

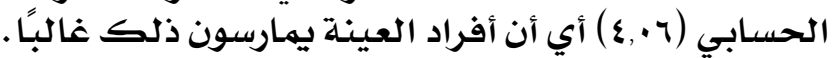

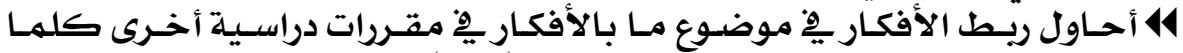

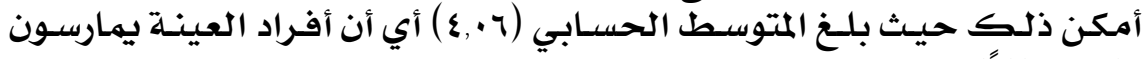
ذلك غالبًا. 


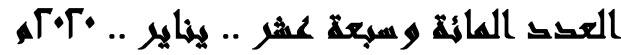

\section{جدول (乏) رأي أفراد العينت حول مهارات التعلم المنظم ذاتيًا}

\begin{tabular}{|c|c|c|c|c|c|c|c|c|c|c|}
\hline \multirow[b]{2}{*}{ الترتيب } & \multirow{2}{*}{ المعياري ال المي } & \multirow[b]{2}{*}{ المتوسط } & \multicolumn{5}{|c|}{ 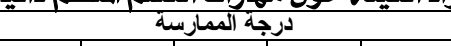 } & \multirow{2}{*}{\multicolumn{2}{|c|}{ 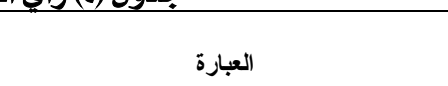 }} & \multirow[b]{2}{*}{ م } \\
\hline & & & أطلاقةً & نادراً & أحيائًا & غالبًا & دائمًا & & & \\
\hline \multirow[b]{2}{*}{9} & \multirow[b]{2}{*}{1} & \multirow[b]{2}{*}{$\varepsilon, \cdot \vee$} & 10 & TA & $11 \pi$ & $r+1$ & ห५. & 5 & \multirow{2}{*}{ 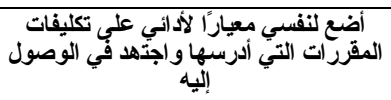 } & \multirow[b]{2}{*}{1} \\
\hline & & & $r, \xi$ & $\leq, 0$ & $1 \Lambda, r$ & rr, t & $\leqslant r, 1$ & $\%$ & & \\
\hline \multirow{2}{*}{$1 \varepsilon$} & \multirow{2}{*}{$1, \cdot \varepsilon$} & \multirow{2}{*}{$r, q \leq$} & 11 & 01 & $1 \% 0$ & IAV & TTY & s & \multirow{2}{*}{ أحدد لنفسي أهدافأ قبل المباثيّرة في تثفيذ } & \multirow{2}{*}{ r } \\
\hline & & & $1, \Lambda$ & $\Lambda, r$ & $r 1,9$ & $\mu \cdot, \mu$ & $r v, \Lambda$ & $\%$ & & \\
\hline \multirow{2}{*}{$1 \cdot$} & $.9 \wedge 1$ & 9.7 & 11 & rq & $1 \pi \cdot$ & 191 & YOY & 5 & أحافظظ على دافعية عالية آتنّاء دراستي & $\mathrm{r}$ \\
\hline & $\cdot, 4 \times 4$ & 8,7 & $1, \Lambda$ & $\xi, V$ & Y1,1 & 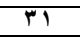 & $\$ 1,0$ & $\%$ & & $r$ \\
\hline$r$ & 14 & 4 & $\varepsilon \pi$ & 1.0 & THY & $1 \leqslant 9$ & $r \cdot \Lambda$ & ك & L & 4 \\
\hline 1. & , & 1,18 & $\mathrm{v}$ & $1 \pi, \Lambda$ & Y $1, \xi$ & $r \leq, 1$ & $r \Psi, V$ & $\%$ & & 8 \\
\hline 19 & I & 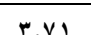 & Yo & $2 \mathrm{~V}$ & 100 & 110 & 110 & 5 & 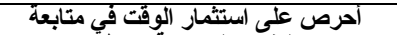 & 0 \\
\hline & Tו, & $r, v i$ & $\varepsilon, 1$ & $1 \cdot, 9$ & ro,1 & $r$. & $r$. & $\%$ & & ${ }^{\circ}$ \\
\hline$r$ & .99 & $\varepsilon, \mu_{0}$ & IT & $r^{T}$ & IV & $1 \leq V$ & riv & s & لياسية & 7 \\
\hline & 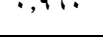 & 2,10 & Y,I & $r, \mathrm{~V}$ & $1 \cdot, 9$ & YT, & 09,0 & $\%$ & (خصص لن & \\
\hline 7 &., $99 \leq$ & $\leqslant 1$. & $\mathrm{v}$ & $r v$ & Irr & 179 & YAI & ك & أسعى للحد من مص & $y$ \\
\hline & 9,748 & 2,10 & 1,1 & 7 & 19,9 & $r V, \varepsilon$ & $\leqslant 0,0$ & $\%$ & & $v$ \\
\hline$r$ & $1<9$ & $4, Y$ & $r$ & 11 & $\wedge 1$ & $1 \pi \leqslant$ & TAY & ك & أحرص على تدوين & $\Lambda$ \\
\hline 1 & $x^{\circ}$ & 8,21 & $\cdot, \Gamma$ & $Y, 9$ & $1 \pi, 1$ & $r, V$ & 71,9 & $\%$ & 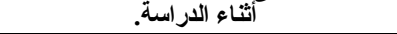 & $n$ \\
\hline ir & $1.0 v$ & $\varepsilon . \mu$ & 11 & ra & TYY & $17 \mathrm{~V}$ & rVI & ك & أطرح الأسئلة حولي إلموضوعات التي أجد & 9 \\
\hline & r & 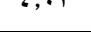 & $Y, q$ & $\overline{7, r}$ & 19,1 & rV, & $\varepsilon r, q$ & $\%$ & 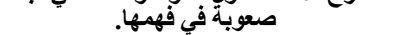 & 9 \\
\hline$\varepsilon$ & $1 . . v$ & & IV & $\varepsilon$ & $\Lambda^{\top}$ & $1 \leqslant \mu$ & rTs & s & 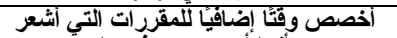 & 1 \\
\hline & $1, \cdot v$ & 2,19 & $Y, \Lambda$ & 8,0 & $1 T, 0$ & YT,Y & $0 \leqslant, 1$ & $\%$ & ل بأنها أصعب من & 1. \\
\hline$\Lambda$ & $1, .0$ & $\leq . .9$ & IY & $\leqslant 4$ & 1.9 & 17. & rq. & s & أتوجه بطلب المساعدة من زميلاتي في فهر & 11 \\
\hline$\wedge$ & $1, .0$ & $2, .9$ & 1,9 & $V, 0$ & TV,V & Yo,q & $\varepsilon V$ & $\%$ & 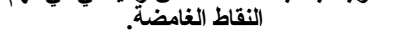 & 11 \\
\hline 1 & I ry & rr & $\sum \Lambda$ & A. & ITr & 100 & $r+1$ & s & أعمل على إعداد ملذصات للمقّر ات التي & 1) \\
\hline 11 & $1, i v$ & r, & $\mathrm{v}, \Lambda$ & $1 \pi$ & Y1,T & $Y 0,1$ & TY,T & \% & & II \\
\hline r & $1, r r$ & $r, r q$ & $7 \varepsilon$ & 1.0 & 10. & IKT & IVo & ك & أحرص على طلب المس & $1 \%$ \\
\hline & & & $1 \cdot, \xi$ & IV & $r \leqslant, r$ & 19,9 & 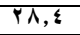 & $\%$ & المقرر لذا لزم الأمر عبر وسائل متعددة. & $\pi$ \\
\hline 14 & 1,17 & ryy & TY & $\mathrm{V} 7$ & $1 \leqslant$ & 104 & TYY & s & أوجه لنفسي أسئلة ذَّية لتقويم تعلمي لكل & $1 \leqslant$ \\
\hline 10 & & $r, r_{V}$ & $r, \mathrm{~V}$ & $T Y, r$ & YY,V & YO,r & $r 4$ & $\%$ & 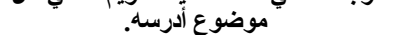 & 18 \\
\hline 19 & 1.9 & $\mathrm{r} A \xi$ & ro & $\leqslant \leqslant$ & $1 \leqslant \Lambda$ & 19. & Yl. & s & أسعى للحصول علد & 10 \\
\hline 17 & 1,4 & $r, \lambda z$ & $\varepsilon, 1$ & $\mathrm{v,l}$ & $r \leqslant$ & $r \cdot, \xi$ & एะ & $\%$ & مستوى أدائي في الآخا & 10 \\
\hline$r$ & L & W IV & 77 & 119 & INT & $1 \leqslant Y$ & $1 \cdot V$ & s & أحرص على درأسة المقررات الدراسية & 17 \\
\hline $1 z$ & $1, \pi$ & Tr & $1 \cdot, \mathrm{V}$ & $19, r$ & rq,V & YT & $T V, r$ & $\%$ & أو أوا بأول. & 17 \\
\hline 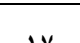 & 1 & & ए๘ & 74 & $1 \times \Lambda$ & $10 \xi$ & THA & 5 & اضع اثتكالا مبسطة ورسوما بياتية & \\
\hline IV & $1, \mu_{1}$ & $\Gamma, \wedge \uparrow$ & 0,0 & $1 \cdot, r$ & $r \cdot, v$ & ro & $r \wedge, \uparrow$ & $\%$ & & iv \\
\hline 10 & $1 . y$ & 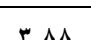 & 11 & OY & $1 \leqslant 0$ & 111 & TYT & s & أحرص على تطوير مهار اتي الدراسية & 14 \\
\hline 10 & $1, \cdot v$ & r & $r, \uparrow$ & $\Lambda, \xi$ & YT,O & rq,r & r., & $\%$ & باستمر ار مستفيدةً من خبراتَّ الآخرين. & $1 \mathrm{x}$ \\
\hline & & & 11 & ra & $11 \mathrm{~V}$ & 170 & rNo & s & 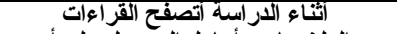 & \\
\hline $\mathrm{v}$ & $1, \cdot r$ & $\varepsilon, .9$ & 1,1 & $ד, r$ & 19 & $r \checkmark, v$ & r... & $\%$ & و الملخصات و أحاول الحصول على أهم & 19 \\
\hline & & & 7 & $\$ 1$ & Trv & $1 \wedge \Lambda$ & $r \leqslant 0$ & S & أحرص على الاستفادةً من جميع مصادر & $r$ \\
\hline ir & $\cdot, 9 \wedge \mathrm{V}$ & $\varepsilon,+1$ & $T$ & 7,7 & TY,Y & $r \cdot, 0$ & rq,V & $\%$ & الآتعلم المتاحة لي. & P. \\
\hline 0 & $\cdot, 9 \vee \vee$ & $\varepsilon, 1 \wedge$ & 11 & $r 1$ & 9. & 191 & rq६ & s & غالبًا أفكر فيما أسمعه أو أقرَّأه لأقرر إذا ما & Y) \\
\hline 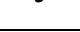 & e trv & $z, \lambda$ & 1,1 & 0 & $1 \varepsilon, 7$ & ri & $\varepsilon \mathrm{V}, \mathrm{q}$ & $\%$ & " كان مقنعًا آم لا. & Tr \\
\hline 1 & . va. & $\{01$ & $\varepsilon$ & 1. & $\pi$ & $15 \mathrm{~V}$ & 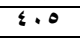 & s & عندما تكوبن المعلومة غير واضحة فِإنني & YY \\
\hline & & 2,01 & $\cdot, 7$ & 1,7 & 9,9 & YY,Y & 70,7 & $\%$ & أعود و أحاول أن أفهمها مرة ثانية. & $\pi$ \\
\hline ro & $1, r_{1}$ & $\pi, 10$ & Ar & IRT & $10 \%$ & $1 \mathrm{TV}$ & IYI & s & أخصص وقَت لمناقُشَّة المقرر الدراسي مع & r \\
\hline 10 & $1, T$ & $P, 10$ & $1 \pi, 0$ & 19,9 & $Y \leqslant, \Lambda$ & YY,Y & 19,7 & $\%$ & مجموعة من الزميلات. & $\pi$ \\
\hline r & $1 \mathrm{rt}$ & 419 & TV & TYY & $1 V \varepsilon$ & 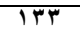 & 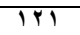 & s & عندما أستذكر دروسي فإنني أجميع & $Y<$ \\
\hline MT & 1,17 & $r, 19$ & $1 \cdot, 9$ & 19,1 & TA,Y & Y1, & 19,7 & $\%$ & المعلومات من مصادَّر مختنتلفة. & 18 \\
\hline & & & IV & $r \varepsilon$ & 1.7 & 197 & Y7६ & S & أحاول ربط الأفكار في موضو ع ما بالأفكار & \\
\hline 11 & $1, \cdot r$ & $\{, . \uparrow$ & $r, \Lambda$ & 0,0 & $I V, r$ & $r, \Lambda$ & $\leq r, \Lambda$ & $\%$ & في مقررات در اسية أخرى كلمًا أمكن ذلك. & ro \\
\hline & & & & & & & & & المتوس & \\
\hline
\end{tabular}




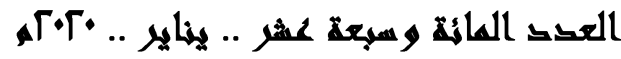

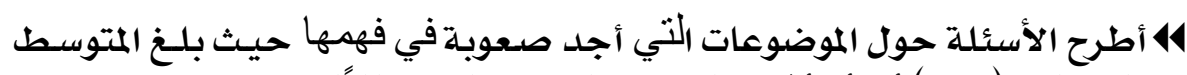

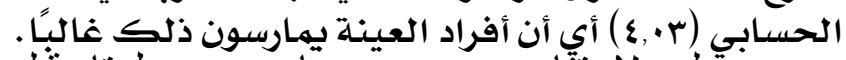

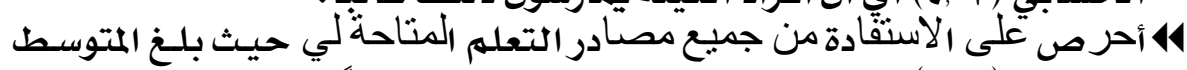

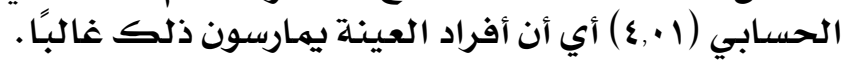

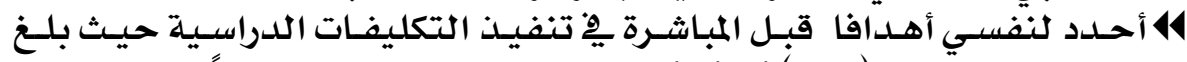

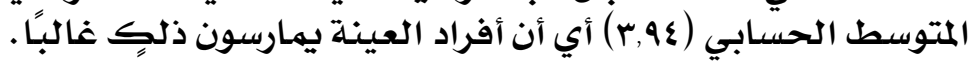

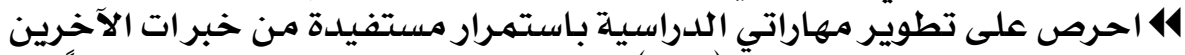

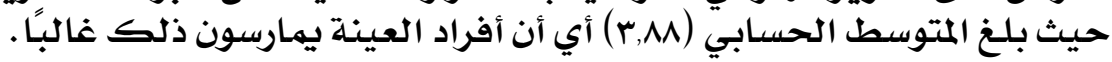

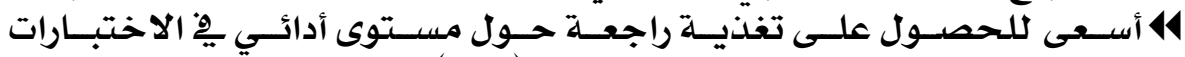

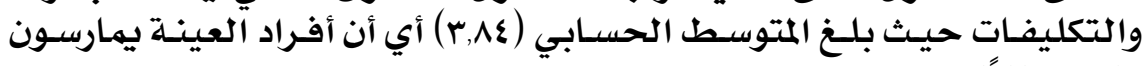
ذلك غالبًا.

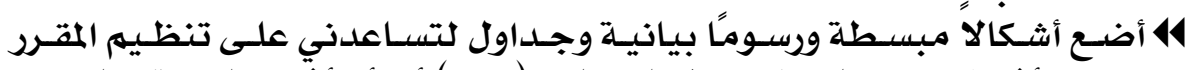

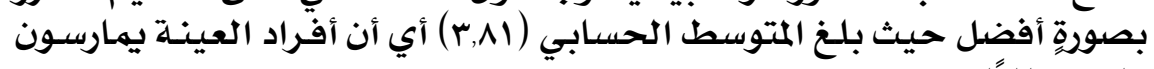
ذانك غالبًا.

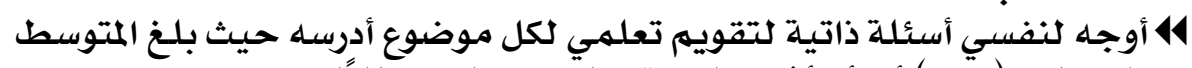

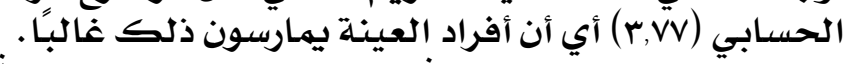

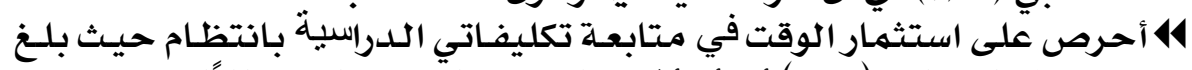

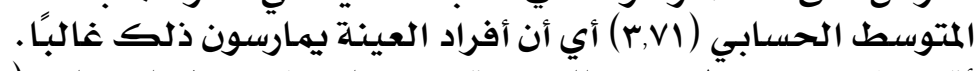

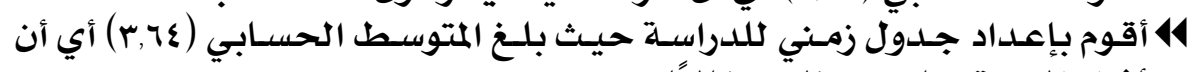

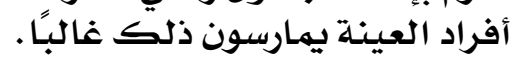

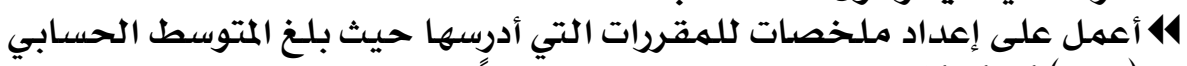

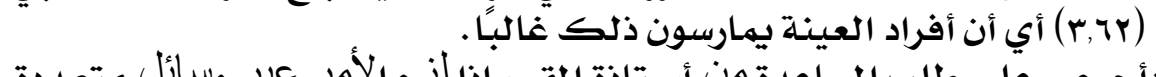

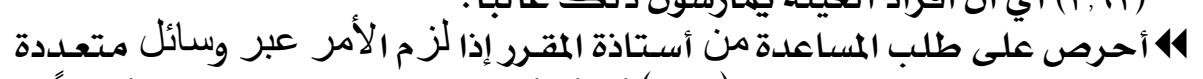

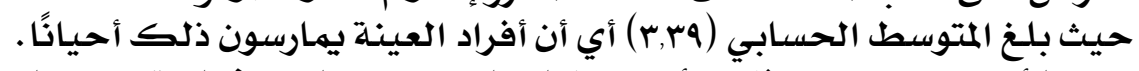

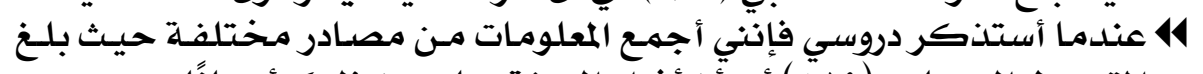

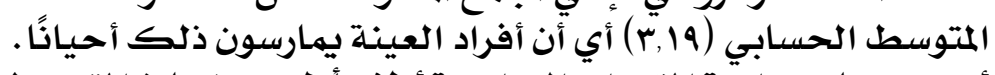

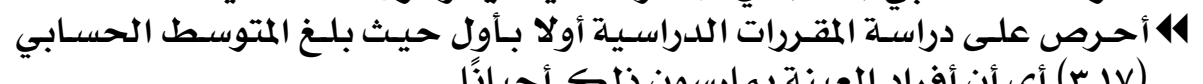

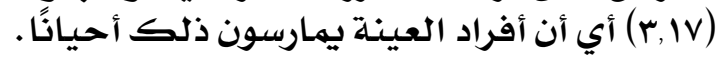

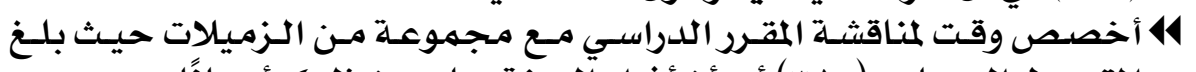

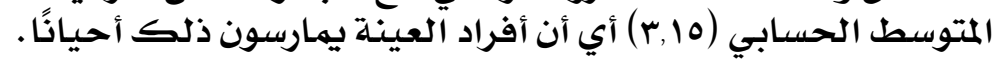

• مناقشة النتائج:

يتضِّح من نتائج البحث أن أفراد العينـة يمارسون مهارات التعلهم المنظم ذاتيًا

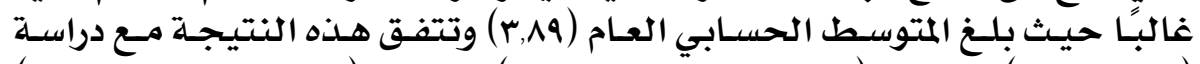

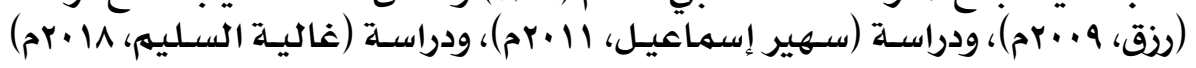

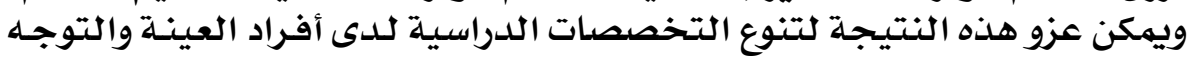

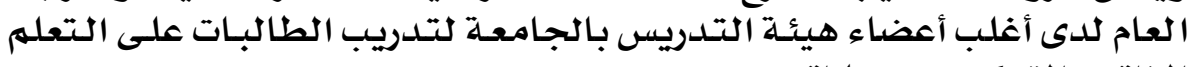
الذاتي والتمكن من مهاراته. 


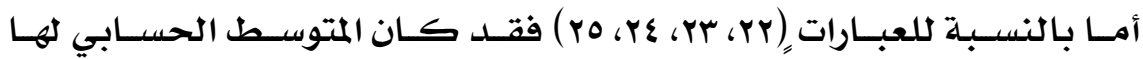

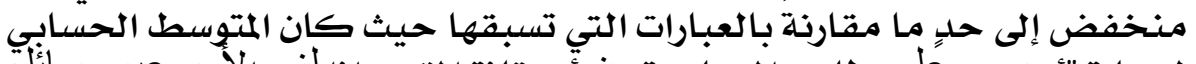

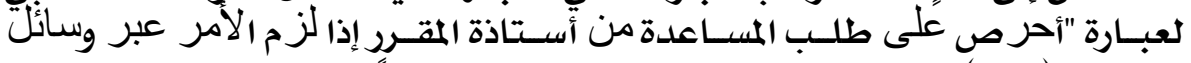

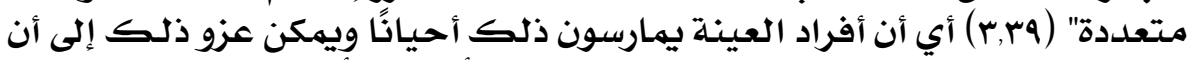

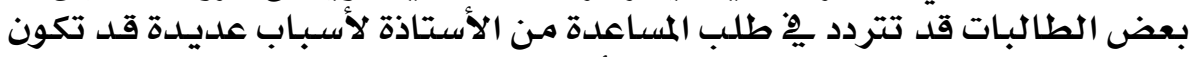

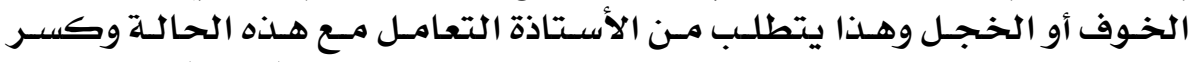

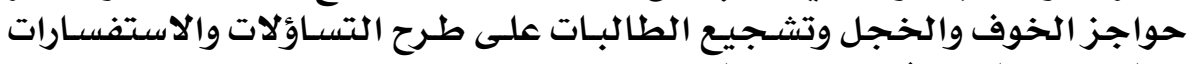

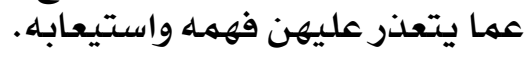

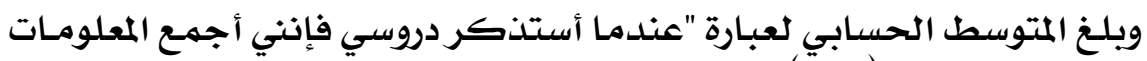

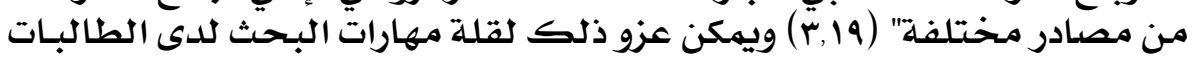

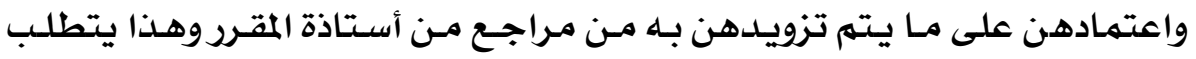

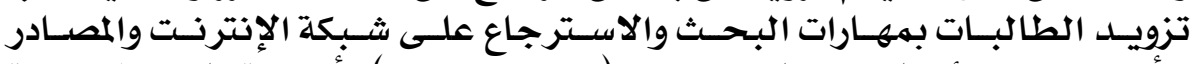

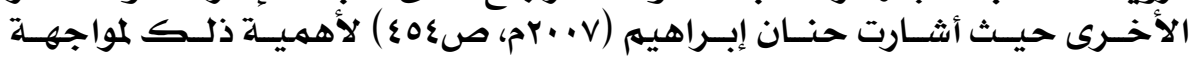

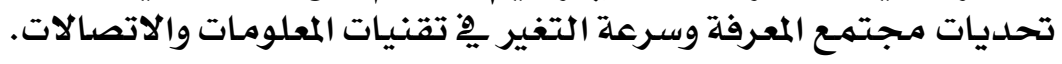

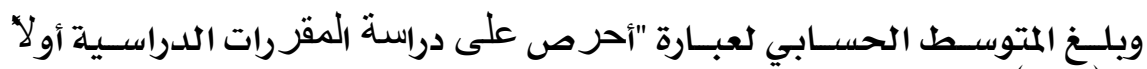

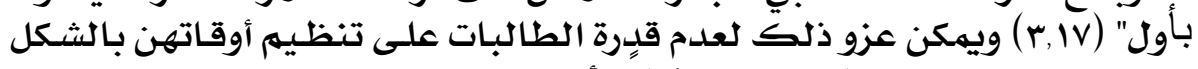

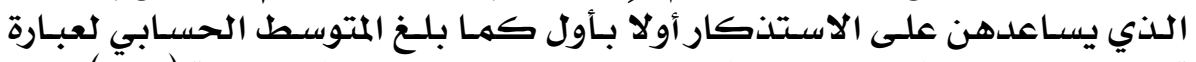

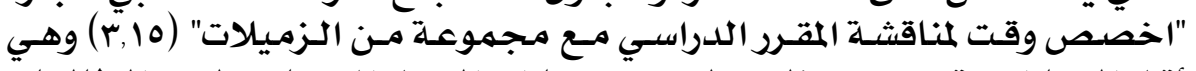

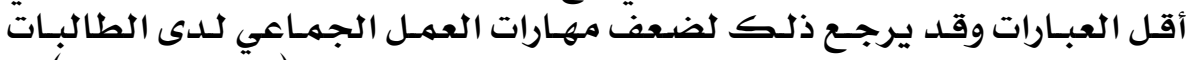

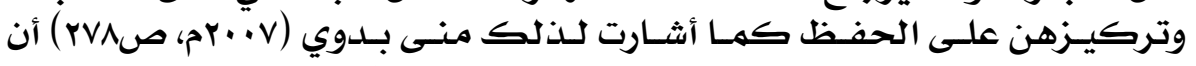

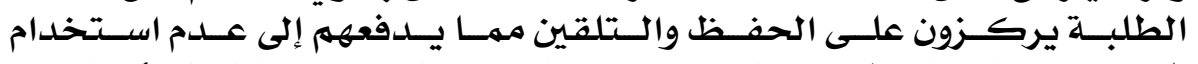

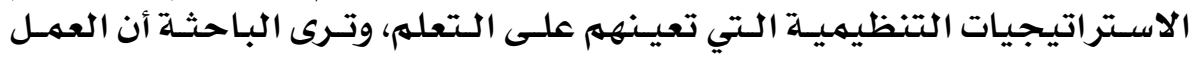

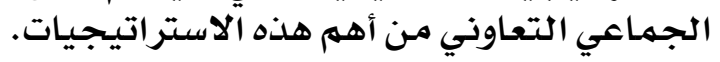

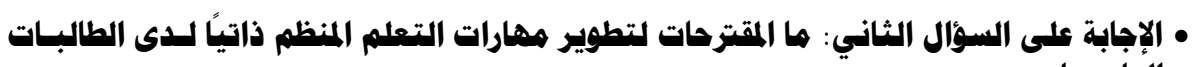
الجاهعيات؟

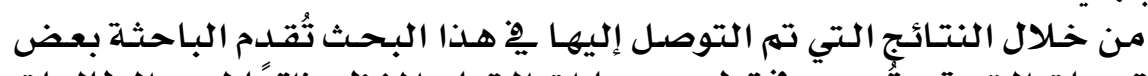

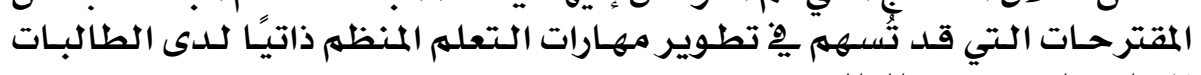
الجامعيات وهي كالتالي: التئي

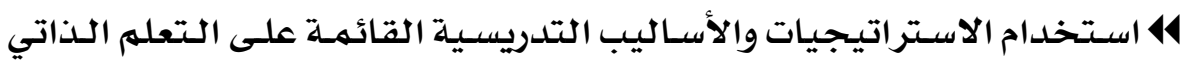

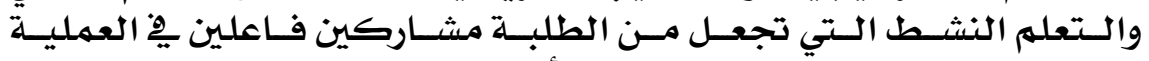

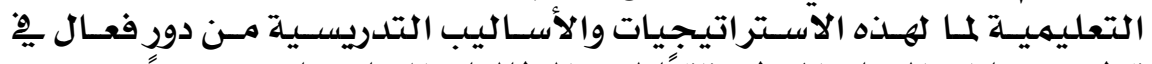

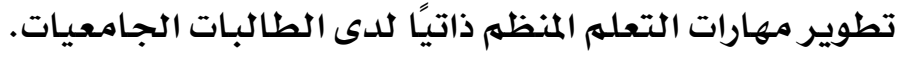

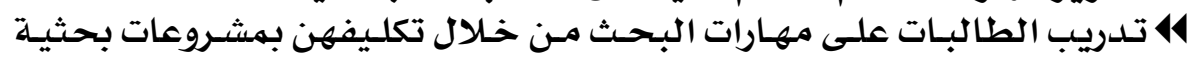

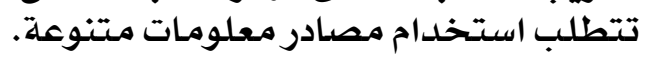

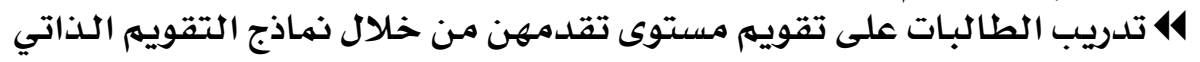




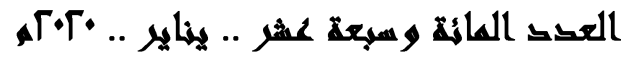

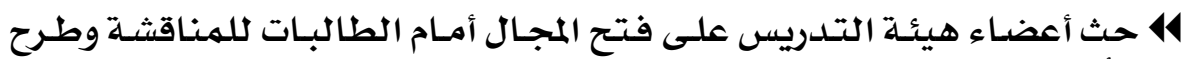

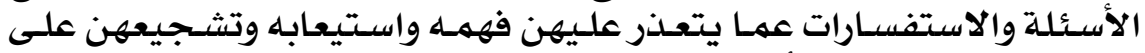

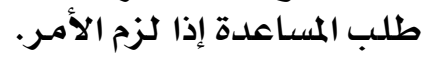

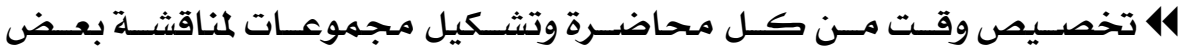

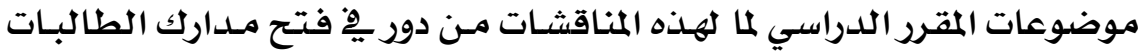

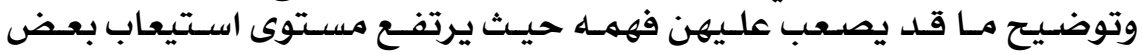

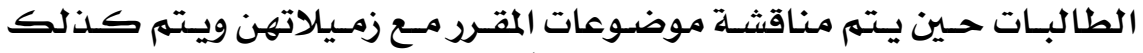

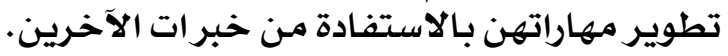

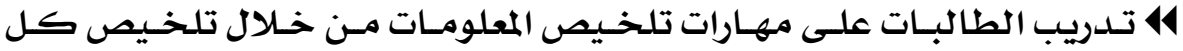

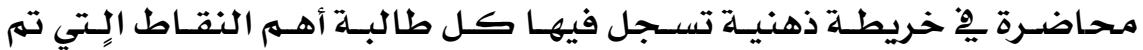

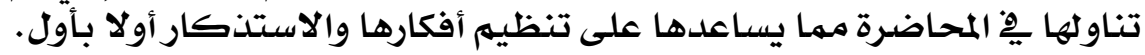

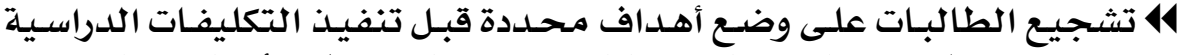

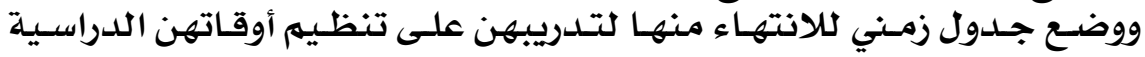

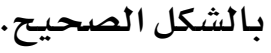

\section{• توصيات الدراستة:}

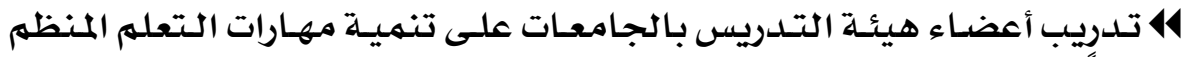
ذاتيًا لدى الطالبـات.

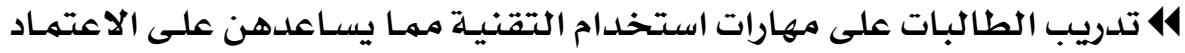

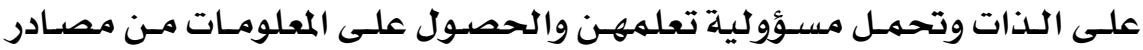

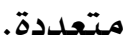

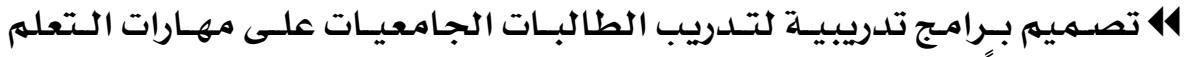
المنظم ذاتيًا.

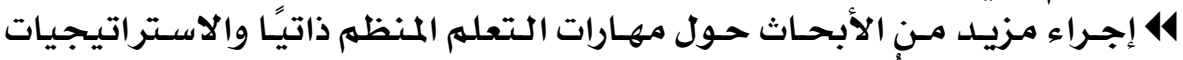

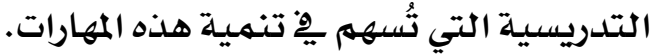

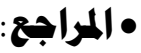

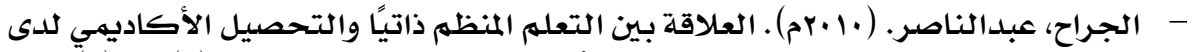

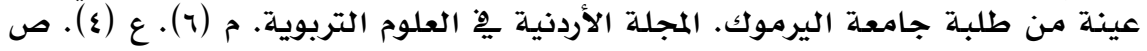
r

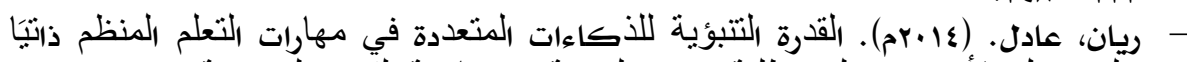

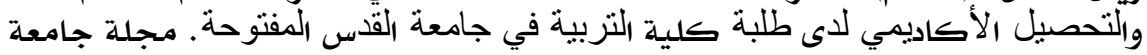

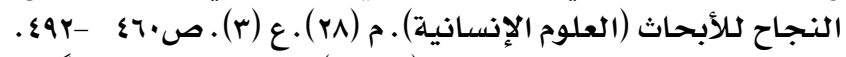

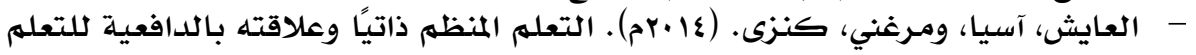

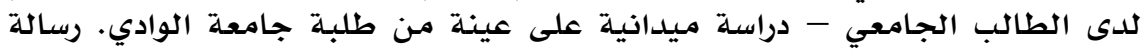
ماجستير · جامعة الوادي الجائ الجزائر.

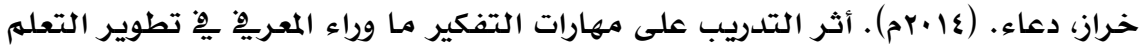

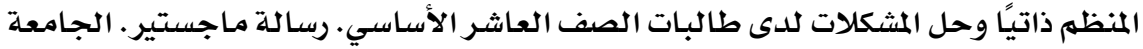

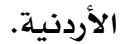




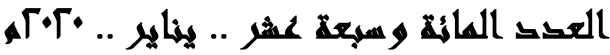

- قطامي، نايفة. (ع . .rم). الاستراتيجيات المعرفية للتعلم المنظم ذاتيًا للطلبة الجامعيين

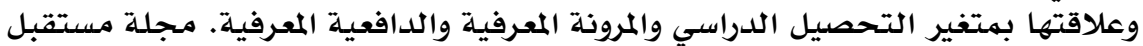

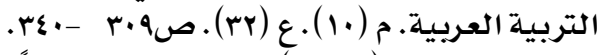

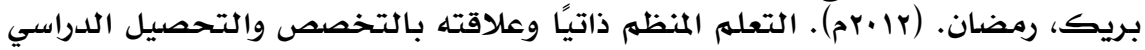

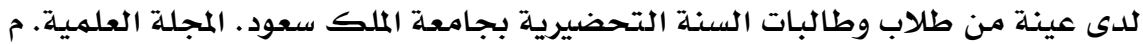
.

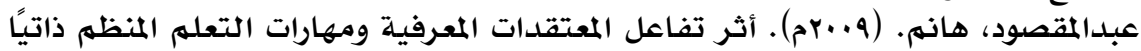

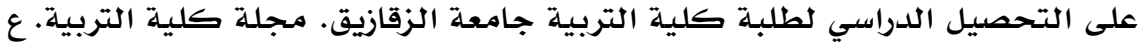

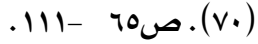

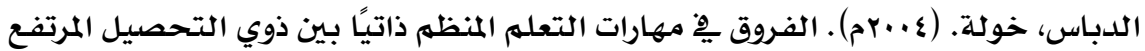

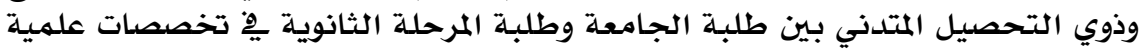

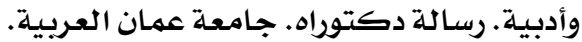

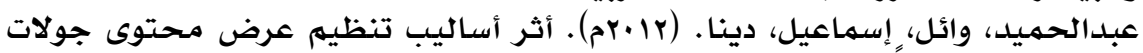

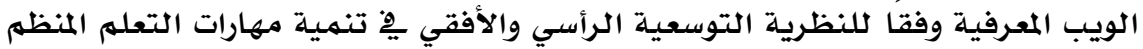

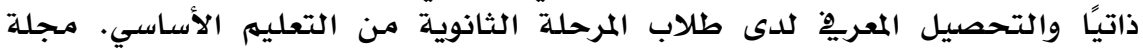

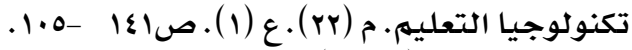

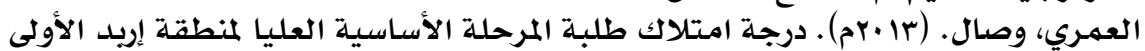

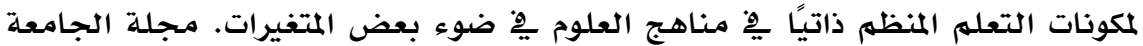

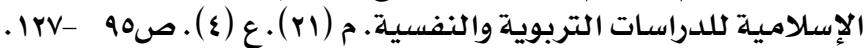

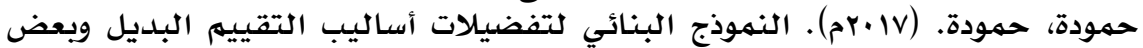

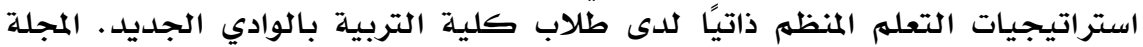

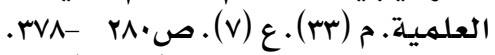

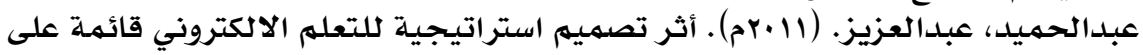

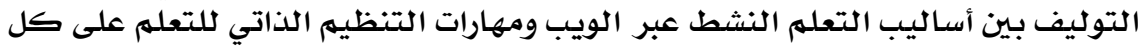

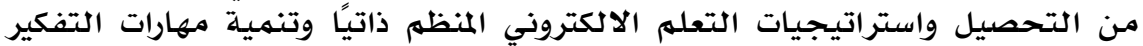

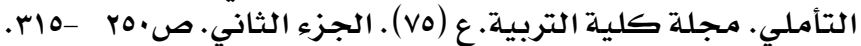

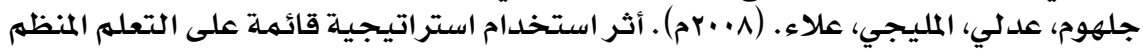

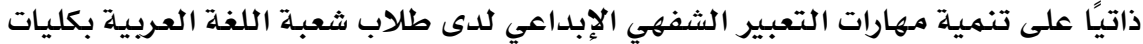

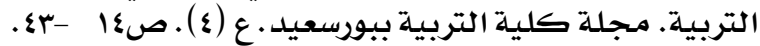

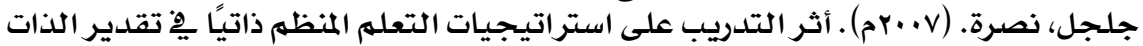

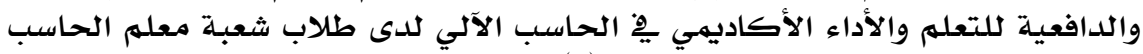

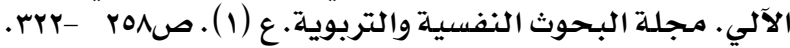

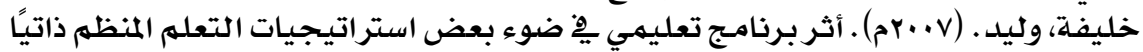

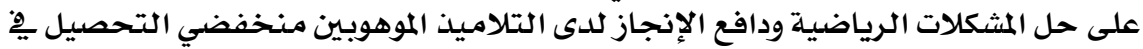

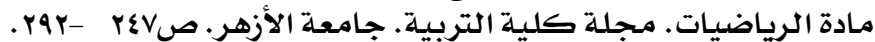

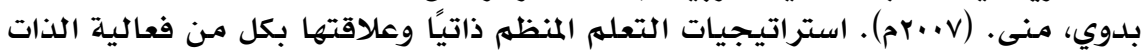

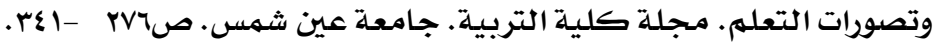

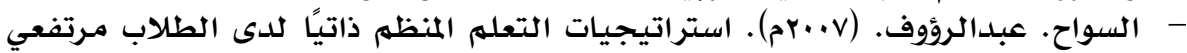

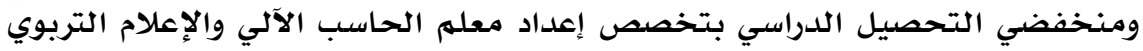




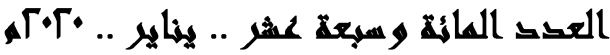

بكلية التربية النوعية. مجلة بحوث التربية النوعية. جامعة المنصورة.ع (.1). صهم - -

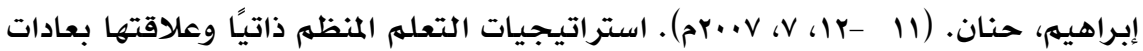

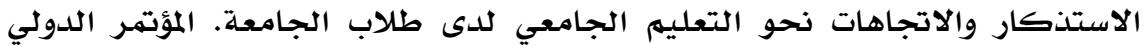

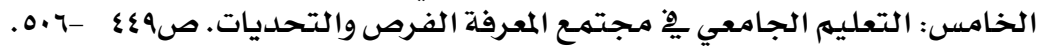

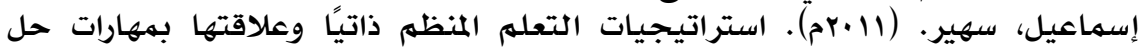

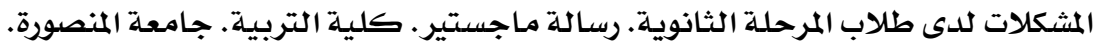

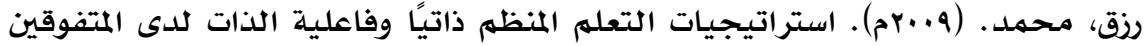

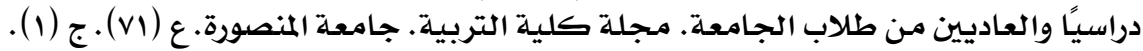
صع - دعـ.

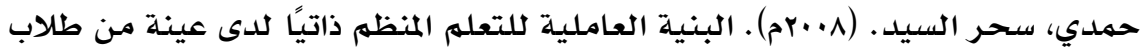

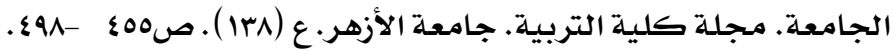

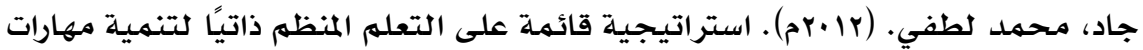

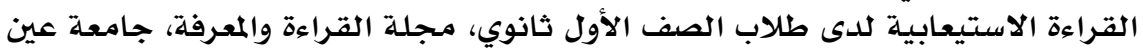

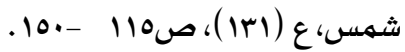

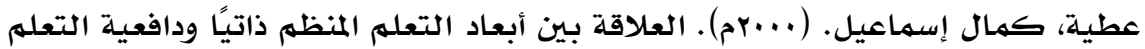

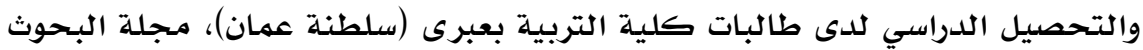

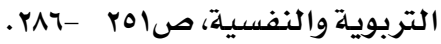

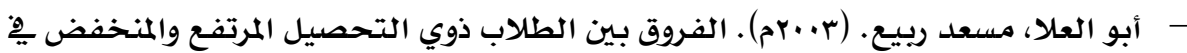

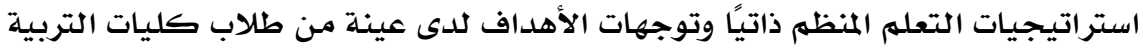

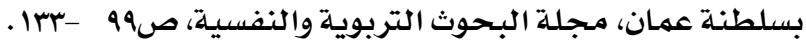

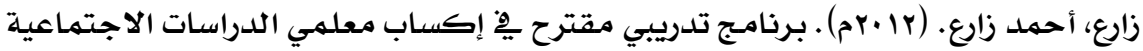

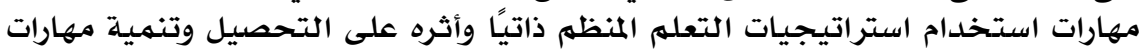

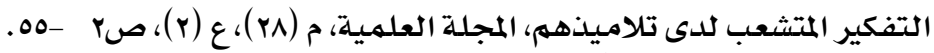

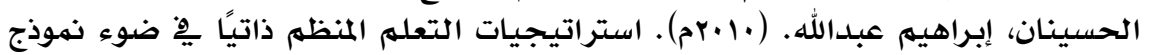

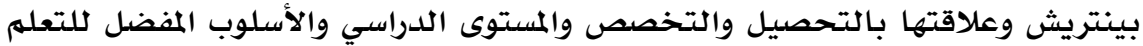

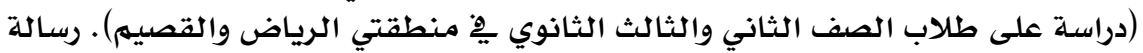

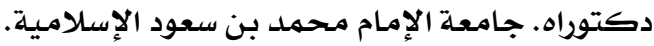

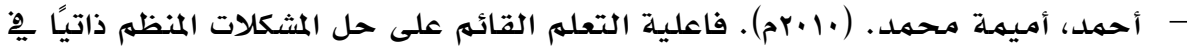

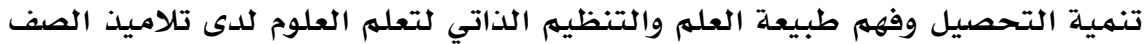

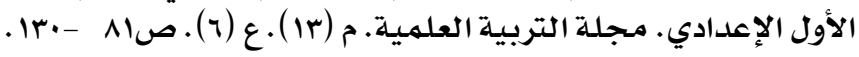

- Nilson, L. B. (2013). What is self-regulated learning and how does it enhance learning? In Creating self-regulated learners: strategies to strengthen students self-awareness and learning skills. Sterling, VA: Stylus Publishing, $1-2$.

- Zimmerman, B. J. (2002). Becoming a self-regulated learner: an overview. Theory into Practice, 41, $64-70$. 
- Ricci, C. (2011). Emergent, Self-Directed, and Self-Organized Learning: Literacy, Numeracy, and the iPod Touch. IRRODL. 12, 136-146.

- Kim, J\& So, K. (2013). Informal Inquiry for Professional Development among Teachers within a Self-Organized Learning Community: A Case Study from South Korea. International Education Studies. 6, 3, 105-115.

- Esteben, P\& Peart, M. (2014). Introducing Self Organized Learning Environments in Higher Education as a Tool for Lifelong Learning. Reasearch Gate.:https://www.researchgate.net/ publication / $\underline{270959639 .}$.

溇楼溇溇溇 